\title{
Review Article \\ Cancer Stem Cells and Macrophages: Implications in Tumor Biology and Therapeutic Strategies
}

\author{
Bruno Sainz Jr., ${ }^{1,2}$ Emily Carron, ${ }^{3}$ Mireia Vallespinós, ${ }^{1,2}$ and Heather L. Machado ${ }^{3}$ \\ ${ }^{1}$ Department of Biochemistry, Autónoma University of Madrid, School of Medicine, 28018 Madrid, Spain \\ ${ }^{2}$ Instituto de Investigaciones Biomédicas "Alberto Sols", CSIC and UAM, 28018 Madrid, Spain \\ ${ }^{3}$ Department of Biochemistry and Molecular Biology, Tulane Cancer Center, Tulane School of Medicine, New Orleans, LA 70118, USA
}

Correspondence should be addressed to Heather L. Machado; hmachado@tulane.edu

Received 19 November 2015; Accepted 31 December 2015

Academic Editor: Seth B. Coffelt

Copyright (C) 2016 Bruno Sainz Jr. et al. This is an open access article distributed under the Creative Commons Attribution License, which permits unrestricted use, distribution, and reproduction in any medium, provided the original work is properly cited.

\begin{abstract}
Cancer stem cells (CSCs) are a unique subset of cells within tumors with stemlike properties that have been proposed to be key drivers of tumor initiation and progression. CSCs are functionally defined by their unlimited self-renewal capacity and their ability to initiate tumor formation in vivo. Like normal stem cells, CSCs exist in a cellular niche comprised of numerous cell types including tumor-associated macrophages (TAMs) which provides a unique microenvironment to protect and promote CSC functions. TAMs provide pivotal signals to promote CSC survival, self-renewal, maintenance, and migratory ability, and in turn, CSCs deliver tumorpromoting cues to TAMs that further enhance tumorigenesis. Studies in the last decade have aimed to understand the molecular mediators of CSCs and TAMs, and recent advances have begun to elucidate the complex cross talk that occurs between these two cell types. In this review, we discuss the molecular interactions that define CSC-TAM cross talk at each stage of tumor progression and examine the clinical implications of targeting these interactions.
\end{abstract}

\section{Introduction}

Cancer stem cells (CSCs), also known as tumor-initiating cells or tumor-propagating cells, constitute a biologically unique subset of stemlike cells within the bulk tumor cell population. These cells are hypothesized to be key drivers of the multistep process of oncogenesis, giving rise to the clonogenic core of tumor tissues. Thus, according to the CSC model of tumor heterogeneity [1], malignancies have a hierarchical developmental structure with the CSC at the top of the hierarchy (Figure 1). This idea that tumor initiation and progression are driven by stemlike cells was first proposed $>150$ years ago by Virchow [2] and has long been debated. While their existence has been confirmed across numerous different tumor entities, including acute myeloid leukaemia [3], pancreatic cancer [4,5], breast cancer [6], lung cancer [7], hepatocellular carcinoma [8], head and neck cancer [9], colon cancer [10, 11], prostate cancer [12], melanoma [13, 14], and glioblastoma [15], the origin of CSCs is not fully understood. This review does not aim to discuss the origin of CSCs, except to point out that whether CSCs arise from normal stem/progenitor/differentiated cells or acquire mutations that confer stem cell-like properties, CSCs should not be confused with normal stem cells becoming cancerous ("cancerous stem cells") [16]. Rather CSCs are believed to have acquired, over time, phenotypes and characteristics of normal stem cells such as unlimited self-renewal and the capacity to divide indefinitely and at the same time maintain the ability to generate multiple cell lineages, including differentiated progenies $[17,18]$. Thus, CSCs are functionally defined by their self-renewal capacity, their multipotency, and their exclusive ability to initiate tumors in mice upon serial passage $[1,16]$.

The clinical implication of the CSC model suggests that only elimination of the CSC will result in eradication of the tumor, while failure to do so will inevitably lead to tumor relapse. This concept is supported by data demonstrating that primary tumors with a clear stem cell signature are consistently associated with poor response rates and relapse [19-22], and CSCs are more resistant to chemotherapy and 


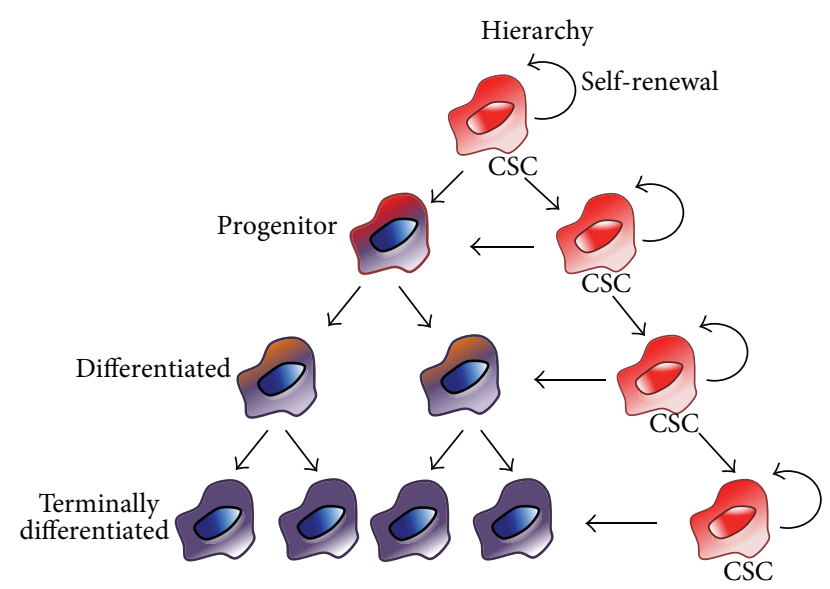

FIgURE 1: The CSC model. Over time, CSCs acquire phenotypes and characteristics of normal stem cells such as unlimited self-renewal and the capacity to divide indefinitely and at the same time maintain the ability to generate multiple cell lineages, including differentiated progenies. A CSC can thus divide (1) asymmetrically (differentiation) giving rise to one CSC and a specialized differentiated cell or (2) symmetrically (self-renewal) giving rise to two identical CSCs. In both cases, the capacity of self-renewal remains intact and ensures the survival of the CSC pool and supports the hierarchical model of tumor cell heterogeneity.

radiotherapy than "differentiated" tumor cells [22, 23], likely due to cellular defense mechanisms shared with normal stem cells [24-26]. Consequently, the idea of eliminating CSCs as a therapeutic strategy is already beginning to revolutionize how we foresee cancer treatment in the immediate future, with CSC-specific compounds expected to lead the battle. However, we are far from achieving this goal, as our understanding of the CSC niche and the cellular determinants that CSCs need for survival is in its infancy.

Like somatic stem cells, CSCs exist in a cellular niche that provides key signals for self-renewal and tumorigenesis [27, 28] (Figure 2). More specifically, the tumor microenvironment protects CSCs from immune surveillance, apoptosis, and chemotherapeutics and above all, the niche provides CSCs with factors that maintain, drive, and promote their "stemness." In general, developing tumors promote the creation of a unique cellular microenvironment containing extracellular matrix proteins (e.g., collagen, elastin) and a diverse collection of cells, including cancer-associated fibroblasts; stellate cells [in pancreatic cancer or hepatocellular carcinoma (HCC)]; immune cells such as myeloid-derived suppressor cells, monocytes, macrophages, and T-cells; and endothelial cells [29-31]. While each cell or environmental component has a particular function on its own, together they create a dynamic niche replete with secreted factors that synergize and cooperate to develop a complex communication network known as cross talk, with the CSC at center stage.

The importance of the tumor microenvironment in promoting cancer initiation and tumor growth has been increasingly recognized over the past decade [31-35]. In addition to providing structural support for tumor development, the tumor-associated microenvironment of many solid tumors provides cues to CSCs that regulate their self-renewal and metastatic potential as well as their resistance to conventional chemotherapeutic agents $[33,36]$. For example, in human breast cancers, recruited mesenchymal stem cells (MSC) interact with breast CSCs through cytokine loops involving interleukin- (IL-) 6, CXCL7, prostaglandin E2, IL-8, or Gro$\alpha$ stimulating their self-renewal capacity $[37,38]$. Stromal fibroblasts present in invasive human breast carcinomas promote tumor growth through elevated SDF-1/CXCL12 secretion [37], and lung stromal fibroblast-derived periostin creates a metastatic niche for breast CSCs [39]. In pancreatic cancer, tumor-associated pancreatic stellate cells create a paracrine niche for pancreatic CSCs via Nodal/Activin secretion [33]. Likewise, hepatic stellate cells in HCC contribute to liver CSC chemoresistance by secreting hepatocyte growth factor (HGF) [40]. These studies provide further evidence that the tumor microenvironment is essential for CSC functions.

An area of great interest is the role of inflammatory cells in the CSC niche. The tumor microenvironment is characterized by chronic inflammation, which, instead of inhibiting tumor growth, favors tumor formation by stimulating cell proliferation, activating CSCs, and promoting metastasis [28, 41]. Leading the tumor inflammatory response are tumorassociated macrophages (TAMs) [42]. A correlation between high numbers of TAMs and rapid disease progression and poor patient outcome has been observed for decades [32, 43, 44]; however, only recently was this paradoxical phenotype explained. We now understand that this correlation is due to TAM-mediated paracrine signaling, in which macrophagederived factors activate the CSC compartment and promote stemlike features of CSCs, exacerbating tumor progression, metastasis, and even CSC chemoresistance. In this review, we focus on the role of TAMs in CSC biology and pathogenesis in solid tumors. We critically discuss the contribution of TAMs on premalignancy, primary tumor CSCs, circulating CSCs, and the initiation of premetastatic niches in distant organs. We also examine the prospects of directly targeting TAMs or disrupting TAM-CSC cross talk for cancer therapy.

\section{Tumor-Associated Macrophages}

Macrophages, a heterogeneous population of innate myeloid cells, originate from monocytic precursors and can undergo specific differentiation/polarization in the blood or within tissues $[45,46]$. In addition to monocytes, the yolk sac and fetal liver represent two additional sources for colony-stimulating factor-1 receptor- (CSF-1R-) dependent macrophages during early development [47, 48]. Macrophages are not static but rather are extremely plastic and can assume multiple phenotypes in response to constantly changing environmental cues (e.g., bacterial infection, wounds, and cancer). From a simplistic point of view, macrophages are polarized towards a classically activated or "M1" phenotype via type I helper $\mathrm{T}$ (Th1) cytokines [e.g., interferon- (IFN-) $\gamma$ ] and/or activation of Toll-like receptors upon engagement with bacterial components (e.g., lipopolysaccharides). M1 macrophages are therefore involved in Thl responses to pathogens and microbes and are characterized by elevated proinflammatory 

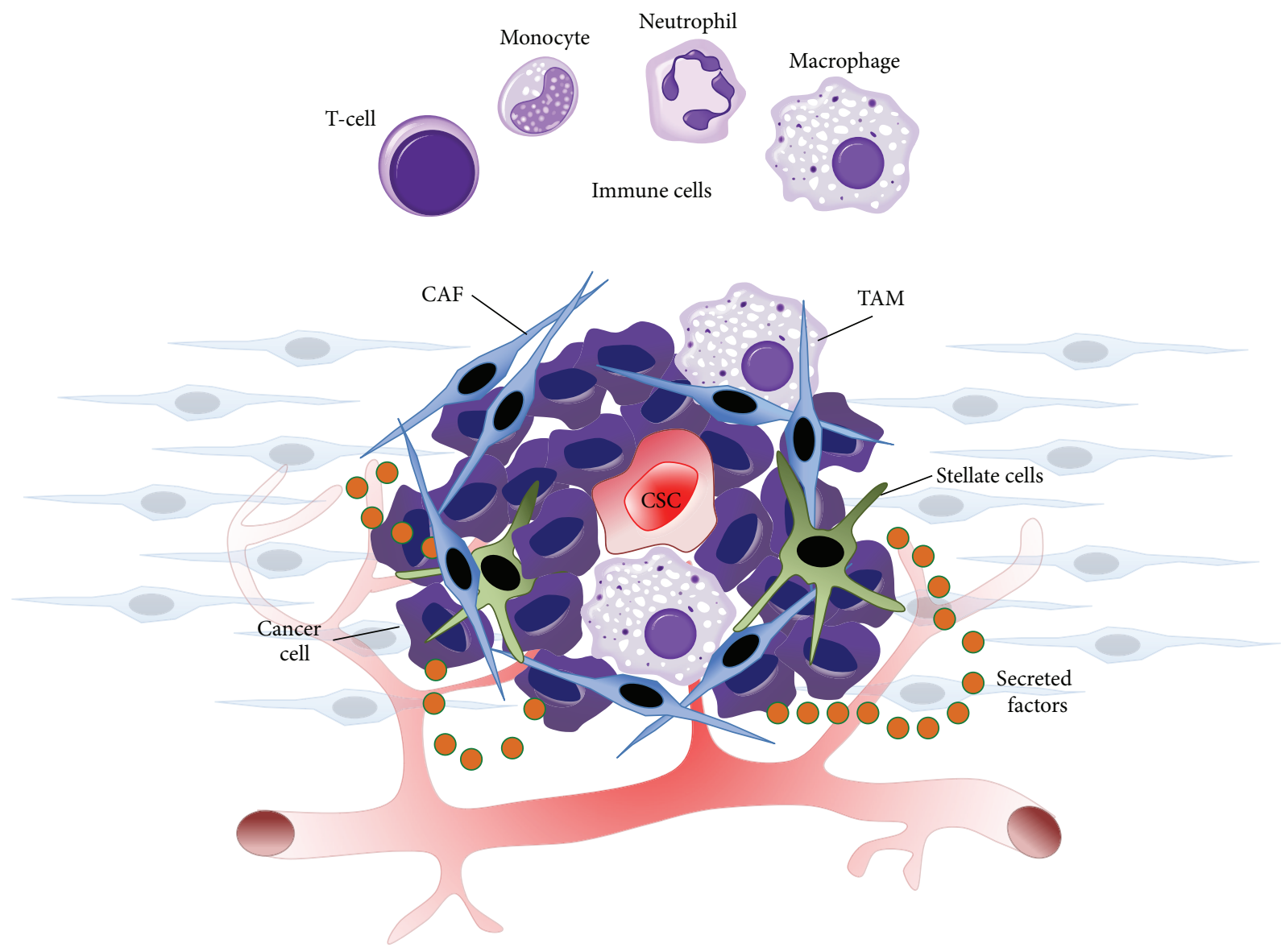

FIGURE 2: The CSC niche and tumor microenvironment. At center stage is the CSC, in contact with a complex and dynamic cellular network, including daughter cancer cells, stellate cells (in the case of HCC and PDAC), cancer-associated fibroblasts (CAFs), and immune cells, which include T-cells, monocytes, neutrophils, and tumor-associated macrophages (TAMs). Nourished by the circulatory system, these cells communicate with one another and directly with the CSC via secreted factors, forming a positive feedback loop that promotes CSC tumorigenicity and metastasis.

cytokines such as IL-12, IL-1 $\beta$, IL-6, and tumor necrosis factor $\alpha$ (TNF- $\alpha$ ), increased expression of major histocompatibility complex (MHC) class II, generation of reactive oxygen and nitrogen intermediates, and enhanced cell killing [49]. In response to IL-4, IL-10, and IL-13, however, macrophages can polarize towards an alternatively activated "M2" phenotype participating in Th2-type responses including humoral immunity, wound healing, and tissue remodeling [50]. They are characterized by high expression of scavenging molecules, mannose and galactose receptors, activation of the arginase pathway, production of IL-10, vascular endothelial growth factor (VEGF), and matrix metalloproteinases (MMPs), and efficient phagocytic activity $[49,50]$ (Figure 3 ).

Monocyte infiltration into a tumor is mediated by chemokines (e.g., CCL2, CCL5, and CXCL12), CSF-1, and components of the complement cascade [51, 52]. Once they are within the tumor, the tumor environment rapidly promotes their differentiation into tumor-conditioned macrophages. TAMs were initially believed to be biased away from an M1 phenotype, expressing M2 protumor markers [53]. We now understand that while they do share greater similarity with alternatively activated M2 macrophages, tumor macrophages are composed of several distinct populations that share features of both M1 and M2 macrophages. Thus, merely classifying tumor macrophages as M1 or M2 does not accurately reflect the differentiated or biological state of TAMs. Rather, the classification of TAMs should be related to the function of the macrophage subpopulation within the tumor (e.g., metastasis-promoting macrophage, angiogenic macrophage, and immunosuppressive macrophage) as has been proposed by others [44, 50, 53, 54]. For such classification purposes, researchers have relied primarily on the analysis of cell surface markers, none of which are entirely restricted to a specific subpopulation or lineage. In the murine setting, the absence of Grl (Ly6G) and the expression of the canonical markers CD11b, F4/80, and CSF$1 \mathrm{R}$ in combination with $\mathrm{mRNA}$ analysis of additional markers (Figure 3) are routinely used to classify macrophage subtypes [44]. In the human setting, antibodies to the glycoprotein CD68, the LPS-coreceptor CD14, CD312, CD115, HLA-DR, or Fc $\gamma$ RIII (CD16) have been used to identify macrophages, but with mixed and oftentimes contradictory results [46]. Combinations of these markers provide higher specificity and should be used when possible to discriminate macrophages 


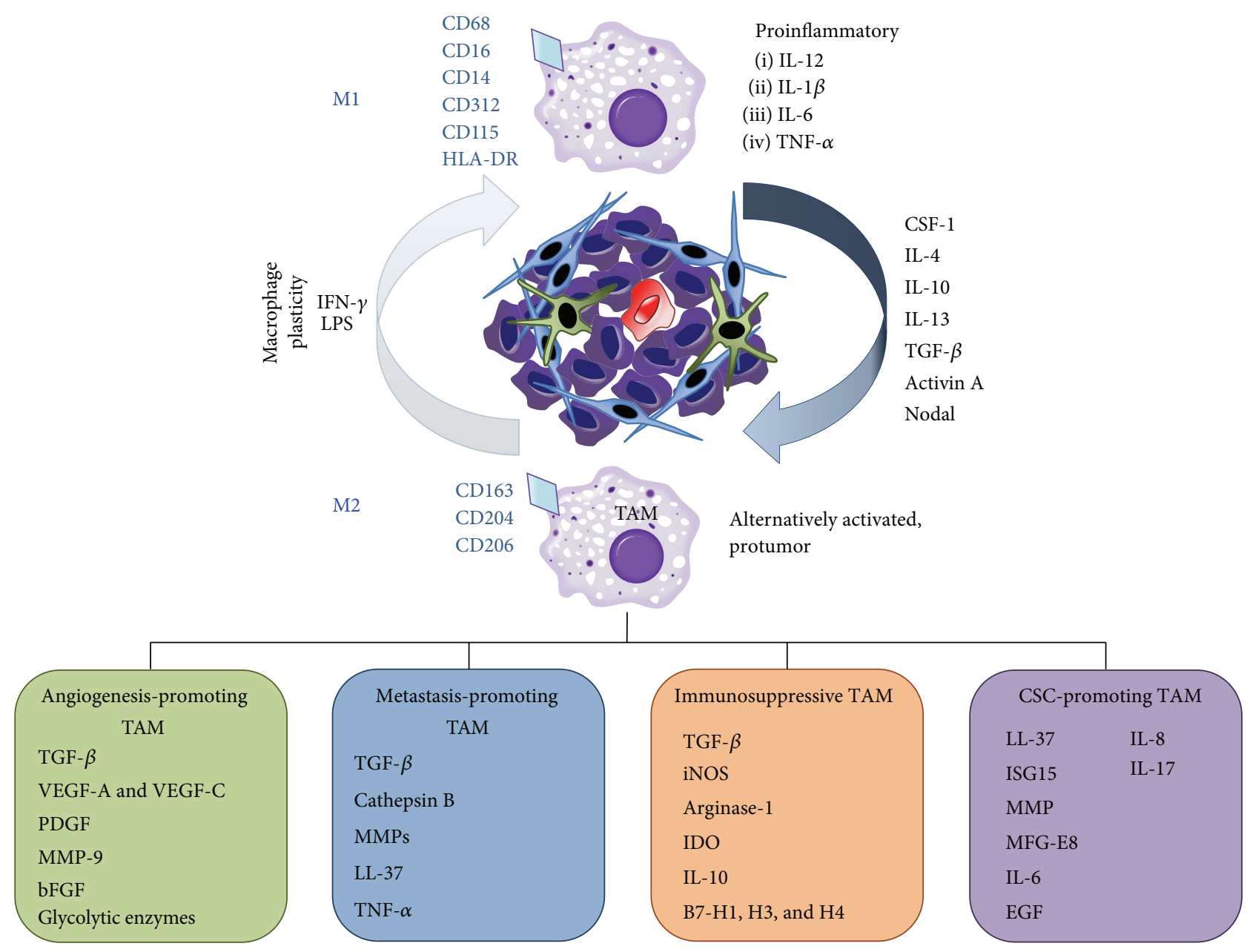

FIGURE 3: Macrophage plasticity and characterization. The binary M1/M2 classification of macrophages suggests that human macrophages exist as either proinflammatory M1 macrophages or protumor M2 TAMs, which can be identified based on the expression of cell surface cell membrane markers. This concept has been challenged by the identification of numerous TAM subtypes (angiogenesis-promoting TAM, metastasis-promoting TAM, immunosuppressive TAM, and CSC-promoting TAM) that exist within the primary tumor and metastatic sites. The existence of a specific TAM subtype is driven by the interaction of macrophages with factors secreted by the tumor microenvironment, leading to transcriptional rewiring of TAMs with a specific gene signature profile. TAMs are highly plastic and can shift between subtypes based on tumor-specific signals and stimuli.

from other myeloid-derived cells, such as polymorphonuclear neutrophils and eosinophils. To more specifically identify M2-like TAMs and subsets, the hemoglobin-scavenger receptor CD163 [55, 56], the macrophage scavenger receptor 1 CD204 [53, 57, 58], the mannose receptor CD206 [59], and more recently the T-cell immunoglobulin and mucin-domain containing protein-3 (Tim-3) [60] have been used with great success. Ultimately, however, there remains considerable controversy regarding how to properly classify and identify TAMs. While classifications based on TAM functions, such as the promotion of angiogenesis or immunosuppression, are now being used to better categorize TAMs (Figure 3), it is important to note that macrophages are dynamic, plastic cells capable of performing many functions simultaneously. Thus, this approach may be self-limiting and underscore the multifunctional capabilities of TAMs. Since the scientific community has yet to come to a consensus regarding what markers to use and how to refer to macrophages, the binary M1/M2 classification remains commonly used [47].

TAMs directly participate in tumor initiation, progression, and metastasis via numerous mechanisms including (1) the secretion of proteolytic molecules such as MMPs to facilitate ECM remodeling [61-64], (2) the expression of nonproteolytic proteins like chemokines $[65,66]$, TGF- $\beta 1$ $[67,68]$, and hCAP/LL-37 $[69,70]$ to facilitate tumor cell proliferation, migration, and invasiveness, (3) the expression of angiogenic mediators such as TGF- $\beta$, VEGF-A, VEGFC, platelet-derived growth factor (PDGF), and MMP-9 to sustain the growth of the tumor stroma and promote de novo tumor blood vessel formation $[44,65,71,72]$, or (4) the expression of immunosuppressive factors including TGF$\beta$, inducible nitric oxide synthase (iNOS), arginase-1, IDO (indoleamine 2,3-dioxygenase), and IL-10 to facilitate T-cell proliferation and activity [73-75]. While the mechanisms 
underlying the protumor effects of TAMs on bulk tumors have been extensively studied, there is now growing clinical and experimental evidence to support that TAMs also enhance tumor progression by directly communicating with CSCs to promote their stemness and/or subsequent oncogenic properties [76].

\section{The Premalignant Niche}

Normal adult stem cells occupy protective niches in various tissues where they function in tissue homeostasis and repair. The activity of stem cells in their tissue-specific niche is regulated by their own intrinsic molecular activity and the signals that they receive from neighboring differentiated cells $[77,78]$. Increasing evidence, discussed below, suggests that macrophages interact with stem cells within their tissuespecific niche to modulate self-renewal and tissue remodeling in both normal and preinvasive tissues.

Alterations in tissue organization and homeostasis can precede tumor initiation, as exemplified by the increased cancer risk associated with chronic inflammation and wound healing. Moreover, epidemiological studies have shown that the administration of nonsteroidal anti-inflammatory drugs (NSAIDs) in low doses results in a significant decreased risk of developing colon, breast, esophageal, Hodgkin's lymphoma, pancreatic, and stomach cancer [79]. Thus, even before cancer begins, chronic inflammation or prolonged inflammatory episodes can set the stage for oncogenesis. The transcription factor nuclear factor-kappa $\mathrm{B}(\mathrm{NF} \kappa \mathrm{B})$ is at the heart of cancer-related inflammation. In inflammatory cells, the $\mathrm{NF} \kappa \mathrm{B}$ pathway results in the induction of numerous tumor-promoting chemokines and cytokines such as IL-6, TNF- $\alpha$, IL-1 $\beta$, CXCL8, VEGF, and CSF-1 [80]. In a mouse model of colitis-associated cancer, suppression of $\mathrm{NF} \kappa \mathrm{B}$ in myeloid cells was shown to significantly decrease the incidence and size of tumors [81]. Subsequent studies showed that activation of $\mathrm{NF} \kappa \mathrm{B}$ in macrophages leads to production of IL-6 and signal transducer and activator of transcription 3 (STAT3) signaling in neighboring cells, which promotes premalignant intestinal epithelial cell survival and CSC proliferation in vivo [82-84]. CCAAT/enhancer binding protein beta $(\mathrm{C} / \mathrm{EBP} \beta)$ transcriptionally activates IL- 6 in epithelial cells and is a direct target of IL-6 in macrophages. Interestingly, $\mathrm{C} / \mathrm{EBP} \beta$ was shown to regulate stem cell selfrenewal and maintenance in the normal mouse mammary gland [85], and C/EBP $\beta$, IL-6, and STAT3 are all overexpressed in preinvasive mammary hyperplasia as compared to normal mammary gland ( $\mathrm{H}$. Machado, unpublished data).

Interestingly, the effect of $\mathrm{NF} \kappa \mathrm{B}$ activation on tumor initiation seems to be cell type-specific. In a diethylnitrosamine$(\mathrm{DEN}-)$ induced model of HCC, mice with I $\kappa \mathrm{B}$ kinase beta(IKK $\beta$-) deficient hepatocytes alone showed a significant increase in tumor number and size, which were characterized by increased reactive oxygen species (ROS), JNK signaling, and hepatocyte death. This cell death stimulated myeloid cells to produce mitogens such as IL-6, TNF- $\alpha$, and HGF, which stimulated proliferation of the surviving hepatocytes. This effect was mitigated either when an antioxidant was administered to these mice or by conditional deletion of IKK $\beta$ in hepatocytes and Kupffer cells [86]. While the role of CSCs in this model is unknown, studies using the normal mammary epithelial cell line, MCF10A, showed that activation of $\mathrm{NF} \kappa \mathrm{B}$ leads to Lin28-mediated repression of Let7, resulting in a biphasic increase in IL-6 and ultimately self-renewal of CSCs [87]. $\mathrm{NF} \kappa \mathrm{B}$ activation in infiltrating macrophages has also been tightly linked to pancreatitis and the development of pancreatic intraepithelial neoplasia (PanIN). During pancreatitis, acinar cells can undergo a transdifferentiation process known as acinar-to-ductal metaplasia (ADM) where their phenotype changes to a duct-like progenitor cell [88]. This process is driven by $\mathrm{NF} \kappa \mathrm{B}$-stimulated macrophage secretion of TNF- $\alpha$, CCL5, and MMP-9 [89]. Once these duct-like progenitors are formed they can progress to PanINs if an oncogenic mutation is acquired, such as in KRAS [90]. Interestingly, a recent study showed that oncogenic KRAS signaling induces intracellular adhesion molecule-1 (ICAM1) expression and the attraction of M1 polarized macrophages. Once recruited, these M1 macrophages promote ADM by secreting TNF- $\alpha$ and MMP-9 [91]. While M1 macrophages are generally believed to be "antitumor," they may also contribute to oncogenic mutations by releasing reactive nitrogen and oxygen intermediates in premalignancy.

During inflammation, macrophages and other infiltrating leukocytes generate high levels of ROS and nitric oxide intermediates that generate DNA damage and genetic instability in epithelial cells. In addition, inflammatory cytokines and ROS deregulate DNA repair enzymes and p53 transcriptional activity leading to microsatellite and chromosome instability [83]. In mouse models with high levels of ROS, hematopoietic stem cells and oligodendrocyte/type 2 astrocyte progenitor cells have dramatically reduced self-renewal capacity due to the expression of senescence related proteins $\mathrm{p} 16^{\text {INK4a }}$ and p19 ${ }^{\text {Arf }}$ [92]. In tumors, CSCs upregulate cellular antioxidants to quench ROS $[93,94]$. While the effect of ROS on CSCs in the preinvasive niche is not known, ROS scavenger proteins in CSCs may help select for their survival in premalignant lesions.

\section{Primary Tumors}

While TAMs in the preinvasive niche contribute to oncogenic transformation and survival, a growing body of evidence suggests that they are critical for the self-renewal and maintenance of CSCs in established tumors. STAT3 and $\mathrm{NF} \kappa \mathrm{B}$ are key regulators of these processes. Once infiltrated into tumors, TAMs contribute to chronic inflammation by secreting inflammatory cytokines, such as IL-1 $\beta$, IL-6, and IL8 (CXCL8) [66, 95-97]. In breast cancer xenografts, IL-6 activates STAT3 by binding to its receptor (gp130) and directly stimulates breast CSC self-renewal [87]. Similarly, binding of IL- 8 to the receptor CXCR1 promotes breast CSC expansion and prevents apoptosis [98]. Both of these cytokines are activated by the $\mathrm{NF} \kappa \mathrm{B}$ pathway and, in a positive feedback loop mechanism, maintain and activate NF $\kappa \mathrm{B}$ [99]. In HCC, TAMs promote the expansion of $\mathrm{CD} 44^{+}$stemlike HCC cells in an in vitro coculture system. Furthermore, TAM-derived IL-6 induced $\mathrm{CD} 44^{+}$stemlike cell expansion by activating 
STAT3, and blocking IL-6 with tocilizumab ablated CD $44^{+}$ sphere formation in vitro and tumor growth in patientderived HCC xenografts [100]. Mitchem et al. showed that ablation of CCR2 or CSF-1R signaling significantly blocked TAM infiltration into pancreatic ductal adenocarcinoma (PDAC), decreased the number of $\mathrm{CD}_{4} 4^{+} \mathrm{ALDH1}^{+} \mathrm{CSCs}$, and improved response to chemotherapy. Infiltrating TAMs also enhanced tumor-initiating properties of $\mathrm{CD} 44^{+} \mathrm{ALDH} 1^{+}$ pancreatic CSCs by activating STAT3 signaling [101].

IL-17 is another proinflammatory cytokine produced by macrophages and T-cells and has been shown to contribute to cancer-associated inflammation in numerous cancers [102105]. Xiang et al. demonstrated that IL-17 promotes the selfrenewal of ovarian $\mathrm{CD}_{133^{+}}$cancer stemlike cells through a mechanism involving $\mathrm{NF} \kappa \mathrm{B}$ and p38 MAPK [106]. Using several different $\mathrm{ER}^{+}$breast cancer cell lines, Ward et al. showed that coculture of M2 macrophages, but not M1 macrophages, increased tumor sphere formation in vitro, although the mechanism by which these macrophages promoted CSC expansion was not tested. Treatment of CSC spheres with zoledronate, a bisphosphonate currently used to treat osteoporosis and bone metastasis, reduced M2 macrophage-mediated sphere formation and migration [107].

The Sox family of transcription factors has also been shown to regulate CSCs in breast cancer. It is well known that a positive feedback loop exists between TAMs and tumor cells, involving epidermal growth factor (EGF) and CSF-1 [108]. Tumor cells secrete CSF-1 that promotes TAM production of EGF, and TAM-derived EGF stimulates tumor cell CSF-1 secretion. In mouse mammary tumor models, TAMs upregulate Sox 2 expression, which increases numerous stem cell genes including Sox-2, Oct-4, Nanog, and Sca-1. Inhibition of the EGF receptor (EGFR1) or STAT3 activation reduced Sox2 expression and CSC-associated phenotypes, suggesting a unique paracrine signaling pathway between TAMs and CSCs [109]. Overexpression of Sox-2 was also shown to increase breast CSC self-renewal by increasing tumor sphere-forming ability in vitro [110]. Sox-4, another pluripotency-associated gene, induced Ezh2 expression [111], which promoted breast CSC expansion by activating Raf-1 and $\beta$-catenin [112].

In addition to mediating CSC self-renewal and expansion, TAMs have been shown to be responsible for the maintenance of the CSC niche. A recent study by Lu and colleagues demonstrated juxtacrine signaling by TAMs and tumor-associated monocytes with mouse mammary CSCs to support the maintenance of a stemlike state [113]. EphH4 binding to its receptor on tumor cells resulted in the activation of $\mathrm{Src}$ and $\mathrm{NF} \kappa \mathrm{B}$, the latter of which caused the secretion of numerous cytokines that function in CSC maintenance. The IL-6/STAT3 pathway was also shown to increase tumor-initiating activities in murine colon and lung cancer cell lines by milk fat globulin epidermal growth factor8 (MFGE-8). TAMs produced large amounts of both MFGE-8 and IL-6, which coordinately induced tumor potential and CSC chemoresistance through STAT3 and Hedgehog signaling, the latter of which regulates normal stem cell selfrenewal. Interestingly, the MFGE- 8 receptor, $\alpha_{\mathrm{v}}$-integrin, was expressed in much higher levels on CSCs as compared to
non-CSCs, further supporting a role for MFGE-8 in CSC maintenance [114].

While numerous studies have demonstrated that TAMs directly regulate CSC self-renewal and maintenance, there is a growing body of research that suggests that, in turn, CSCs recruit macrophages to solid tumors and enhance a protumor phenotype in TAMs. Zhou et al. recently showed that the extracellular matrix protein periostin is preferentially

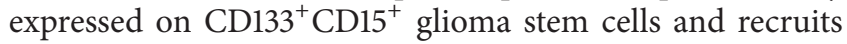
macrophages through integrin $\alpha_{\mathrm{v}} \beta_{3}$ from the peripheral blood to the brain. Deletion of periostin in glioma stem cells resulted in decreased M2 TAM density, reduced tumor growth, and consequently increased survival in glioblastoma xenografts [115]. In pancreatic cancer, primary human PDAC CSCs (spheres) produce IFN $\beta$, which then induces the secretion of IFN-stimulated gene 15 (ISG15) in recruited TAMs. Consequently, TAM-derived ISG15 induced CSC selfrenewal and tumor-initiating properties [116]. More recently, Sainz Jr. et al. demonstrated that PDAC CSCs secrete the TGF- $\beta$ superfamily members Nodal/Activin A and TGF- $\beta 1$, which then induce an M2 macrophage phenotype. Coordinately, polarized TAMs secrete the antimicrobial peptide hCAP-18/LL-37, which consequently binds to its receptors (formyl peptide receptor 2 (FPR2) and P2X purinoceptor 7 receptor $(\mathrm{P} 2 \mathrm{X} 7 \mathrm{R}))$ to enhance CSC self-renewal, invasion, and tumor-initiating properties [70]. Of note, pancreatic CSCs also overexpressed two LL-37 receptors, further indicating a role for LL-37 in pancreatic CSC maintenance. In a different study, it was shown that PDAC CSCs induce an immunosuppressive phenotype in TAMs through STAT3, ultimately leading to chemoresistance [101]. Notably, the MFGE-8 receptor, which was shown to be preferentially expressed on CSCs in colon and lung cancer cell lines, can induce M2 polarization of macrophages in vitro though STAT3 signaling [117]. In summary, there exists a complex relationship between CSCs and TAMs in established tumors. It appears that macrophages are not just accidental passersby that happen to secrete CSC-promoting factors, but rather, CSCs attract, reeducate, and put macrophages into their service to support primary tumor growth. While researchers are just beginning to unravel the intricacies of these processes, there is no doubt that CSC-TAM cross talk represents an important component of CSC-mediated oncogenesis.

\section{Circulating Cancer Stem Cells}

Distant metastases have become the leading cause of death in patients diagnosed with cancer. Metastatic spread begins with cancer cells [known as circulating tumor cells (CTCs)] detaching from the primary tumor and entering into circulation, via either blood vessels or lymphatic channels in order to colonize distant sites. These cells must acquire the ability to overcome the challenges of the hostile extratumoral conditions and adapt to different tissue environments in secondary distant organs, such as the lungs, bone marrow, or liver. It is now commonly accepted that TAMs facilitate almost every step of the metastatic cascade, from initial migration to intravasation, dissemination, extravasation, and establishment of metastasis at secondary sites [44, 51]. One 
of the first definitive studies to highlight the role of TAMs in tumor metastasis was shown by Lin and colleagues in 2001. They demonstrated that CTC levels and lung metastases were significantly decreased in CSF-1-deficient mice as compared to wild type mice, supporting a role for tumor infiltrating macrophages in metastasis [118]. Additional studies targeting macrophages with clodronate liposomes, for example, have shown that elimination of macrophages significantly impacts CTC numbers and tumor metastasis $[119,120]$.

Once free from the tumor, CTCs can disseminate to distant organs to produce secondary metastatic lesions. Interestingly, only a minority of CTCs exhibit the capacity to successfully disseminate and proliferate in different organs, suggesting an internal hierarchy within CTCs. In fact, the existence of a small subset of CTCs with CSC properties has been shown for metastatic breast cancer [121], prostate cancer [122], small cell lung cancer [123], and PDAC [5], supporting the idea of a CSC compartment within CTCs that are distinct from CSCs of the primary tumor, enabling their escape to distant organs and subsequent growth. If this hierarchy within CTCs holds true, then TAMs likely facilitate the emergence of circulating CSCs and their intravasation and subsequent dissemination. The question remains, how do TAMs facilitate these processes in CSCs? While more studies are needed, a number of experimental systems are beginning to provide evidence that TAMs can promote an epithelialto-mesenchymal transition (EMT) phenotype in CSCs via paracrine-secreted factors. Loss of epithelial differentiation, the acquisition of a migratory phenotype, and loss of cell adhesion are hallmarks of EMT. This process is regulated by numerous genetic modifications and a panel of well characterized transcription factors, such as SNAIL, TWIST, ZEB1, ZEB2, SLUG, BMI-1, and LOXL2 [35, 124, 125]. While numerous studies have shown that TAMs can promote an EMT phenotype in non-CSCs [68, 126-131], TAM-mediated EMT induction in CSCs was largely unappreciated until recently. In the context of pancreatic cancer, two recent studies showed that CSCs isolated from patient-derived PDAC xenografts and treated with conditioned media from M2polarized monocyte-derived macrophages increased migration and expression of EMT genes [70, 116]. The authors identified the human cathelicidin antimicrobial peptide LL37 and ISG15 as independent TAM-secreted mediators of these phenotypes in pancreatic CSCs. Similar TAM-mediated EMT induction has been observed in CSCs of HCC [126] and ovarian cancer [69]. STAT3 activation of target genes such as TGF- $\beta 1$ and hypoxia inducible factor- (HIF-) $1 \alpha$ has been linked to EMT reprograming [132] and several recent studies have shown that TAM-secreted IL-6, EGF, or MFGE8 can activate STAT3 signaling in CSCs of breast cancer $[109,133]$, HCC [100], or colon cancer [134]. Thus, apart from activating these pathways in CSCs to promote tumor growth as discussed above, TAM-mediated STAT3 activation may also be necessary for EMT reprogramming in CSCs. While the aforementioned studies highlight that EMT and "stemness" may go hand in hand, the implications reach beyond merely the induction of a migratory and invasive phenotype. For example, EMT transactivators have been associated with the maintenance of stem cell properties and cell survival [135], and more recently EMT induction has been shown to produce de novo breast CSCs [135] and to facilitate CSC maintenance in pancreatic cancer [136]. Thus, while the TAM-mediated induction of EMT in CSCs is likely necessary for the generation of migratory CSCs with invasive capacities, the implications of an EMT transcriptional signature in CSCs may be more dynamic than previously thought.

In addition to paracrine-mediated signaling, juxtacrine signaling from macrophages represents an alternate means by which TAMs can communicate with CSCs. Intravital imaging revealed that tumor cells and macrophages interact in a contact-dependent manner and comigrate in vivo, tumor cell migration is dependent on juxtacrine signaling, and the efficient long-distance comigration and eventual intravasation of these cells are coordinated by an EGF-CSF1 paracrine loop [reviewed in [137]]. Along these lines, Lu et al. recently showed that TAMs physically interact with mouse breast CSCs via CD11b binding to the CSC marker CD90, leading to ephrin ligand binding to EphA4, the activation of Src and $\mathrm{NF} \kappa \mathrm{B}$, and the subsequent secretion of various cytokines that, in turn, function to maintain the stemlike state of CSCs [113]. Taken together, these cell-cell contactdependent interactions provide evidence of a physical CSC niche supported by TAMs; however, it is also plausible that, apart from merely interacting, CSCs and TAMs may actually fuse with one another to create a macrophagetumor circulating cell with recombination/reprogramming of genetic material [138], analogous to that observed in stem cell fusions studies [139]. This concept, loosely known as epithelial-myeloid transition [140], was first proposed by the German pathologist Otto Aichel in 1911 to explain how a cancer cell could efficiently travel through the circulatory and lymphatic systems, while maintaining their cancer cell growth properties. Since then, the concept has slowly gained momentum [141, 142]. However, with the recent discoveries of CTCs expressing both cancer and leukocyte cell markers [143-145], the idea of "mobile hybrids" resulting from fusion events between TAMs and tumor cells is evolving as a more tangible explanation behind metastasis. Regardless of how TAMs promote CSC invasion, as stated by Qian and Pollard, macrophages "are the key that unlock the gate to allow tumor cells to escape” [44].

\section{Premetastatic Niche}

While many tumor cells have a predilection for metastasis, only a small percentage of CTCs (less than $0.2 \%$ ) have the capacity to survive in circulation, find a suitable secondary site to support their colonization, and proliferate in their new environment [146]. In fact, apoptosis of tumor cells entering target organs represents a common early event during metastasis $[147,148]$, severely limiting the colonization efficiency of CTCs. Thus, while successful intravasation initiates the metastatic process, efficient survival and proliferation determine the outcome. The "seed" and "soil" theory put forth by Paget in 1889 suggested that the secondary organs themselves provide the appropriate conditions (i.e., "soil”) necessary for metastatic colonization by CTCs. Our current take on Paget's theory now combines "organ selectivity" with "cell fitness," 
meaning that CTCs must also be genetically (i.e., accumulate specific mutations) or epigenetically programmed for metastasis. CSCs inherently possess the necessary "fitness" and programs for dissemination, and at the same time they bear the functional plasticity needed for transitioning between mesenchymal-like and epithelial-like states [149], the latter being necessary for CSCs to seed and resume growth at the metastatic site. In 2006, Balic et al. first linked metastasis to CSCs by demonstrating that disseminated breast cancer cells in bone marrow possessed stem cell phenotypes [150]. One year later, Hermann et al. showed that tumor metastasis in PDAC is driven by a distinct subpopulation of $\mathrm{CD}_{13} 3^{+}$ $\mathrm{CXCR}^{+}$CSCs in the invasive front [5]. Today, CTCs have been shown to coexpress EMT and multiple stem markers, suggesting that CSCs are present within the CTC population [151].

In light of ever growing data supporting a role for CSCs as the "seed," CSCs are also susceptible to the harsh conditions faced during dissemination and not all cells bearing CSC markers are metastatic. Thus the "soil" counterpart of Paget's theory must also be important for CSC-mediated metastasis. Indeed, it has become evident that the formation of CSC-promoting premetastatic niches in secondary organs is not only essential but also necessary for successful CSC colonization, and current evidence suggests that resident or infiltrating immune cells, specifically macrophages, at distant sites drive the creation of premetastatic niches to facilitate successful establishment of secondary lesions. One of the earliest studies to support this hypothesis showed that not only do macrophages facilitate the growth of extravasated tumor cells, but also their elimination after initial cancer cell dissemination had been established led to a significant decrease in lung metastasis. Thus, the presence of macrophages in secondary organs is necessary for successful CTC extravasation, establishment, and growth [152].

Whether TAMs are present before the arrival of circulating CSCs or whether they are recruited following CSC extravasation remains unclear. In mouse lung or melanoma subcutaneous tumors, $\mathrm{CD} 1 \mathrm{~b}^{+}$myeloid cells accumulate in the lungs prior to the detection of metastatic tumor cells [153]. In studies using a genetically engineered mouse model of PDAC, infiltration of $\mathrm{F} 4 / 80^{+} \mathrm{CD} 1 \mathrm{~b}^{+}$macrophages in the livers of mice was observed months before tumor development and metastatic growth (M. Vallespinós and B. Sainz Jr., unpublished data). There is increasing evidence that more differentiated myeloid cells also play an important role in the development of the premetastatic niche. Specifically, van Deventer et al. observed that the recruitment of $\mathrm{CD}_{11 \mathrm{~b}^{+}} \mathrm{Ly}_{6 \mathrm{C}}{ }^{+}$monocytes to the premetastatic lung enhances B16 cell metastasis [154], and Gil-Bernabé et al. demonstrated

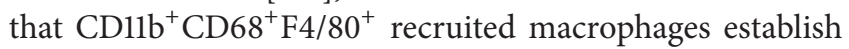
the premetastatic niche that facilitates successful breast cancer metastasis to the lungs [155]. It remains to be determined if the sum of these findings holds up in the human setting. Until then, it is interesting to speculate that primary tumorderived secreted factors, such as soluble proteins or exosomes [156], precondition the premetastatic sites in different organs by preloading them with recruited myeloid progenitor cells. Once recruited to these sites, they can rapidly differentiate into metastasis-associated macrophages (MAMs) following the arrival of circulating CSCs, thus facilitating CSCs extravasation, survival, and subsequent proliferation via paracrinemediated mechanism [157]. It is also important to note that, like TAMs in the primary tumor, MAMs may also facilitate CSC survival from immune cell destruction via the immunosuppressive mechanisms discussed above. Thus, the contribution of macrophages in the premetastatic and their influence in the development of metastatic lesions may be more important than their role in the primary tumor.

\section{Therapeutic Strategies}

Cancer has been treated with radiation therapy, chemotherapeutic drugs, and hormonal therapy for decades; however, these treatments are not tumor cell-specific and can result in severe toxicity. Tumor cells have acquired the ability to circumvent the effects of conventional therapies, leading to resistance to anticancer therapies. While there has been a recent explosion in the field of developing targeted molecular therapies that specifically block tumor cell growth and progression, a subset of cells can evade the effects of these drugs, leading to drug-resistance and/or tumor relapse. The question remains as to whether we are targeting the right population of cells.

Numerous antimacrophage strategies, including trabectedin [158], RG7155 (anti-CSF-1R) [159], and an anti-MIF (macrophage migration inhibitory factor) antibody [160], have been developed and are currently being tested in preclinical and Phase I clinical trials. However, the CSC model suggests that effective therapeutic strategies must target CSCs to not only eliminate tumor progression, but also prevent tumor recurrence after therapy. As the tumor microenvironment provides CSCs with protection from conventional therapies by promoting their "stemness" and CSCs enhance protumor properties of TAMs, disrupting CSC-TAM cross talk, or using a combined strategy to target both CSCs and TAMs, represents an exciting and promising approach for cancer therapy. A recent study demonstrated that cancer stemlike cells from chemoresistant tumors release proinflammatory cytokines that contribute to a protumor microenvironment by generating M2-like myeloid cells [161]. Mitchem and colleagues showed that targeting TAMs in PDAC reduced both CSC properties and chemoresistance [101]. These results suggest that targeting the CSC-TAM interaction is crucial for not only preventing tumor progression, but also circumventing chemoresistance.

One of the most promising antibody-mediated therapeutic strategies to date is based on inhibiting the interaction between $\operatorname{SIRP} \alpha$ and CD47, a transmembrane protein expressed on many cancer cells and CSCs [162, 163], to allow for increased phagocytosis of cancer cells. Interaction of CD47 ("don't eat me" signal) with $\operatorname{SIRP} \alpha$ results in the inhibition of phagocytosis by macrophages (including TAMs) through a signaling cascade mediated by phosphorylation of the immunoreceptor tyrosine-based inhibitory motif present on the cytoplasmic tail of SIRP $\alpha$ [164]. Numerous studies over the past few years, predominantly led by Weissman and colleagues, showed that blocking CD47 using anti-CD47 


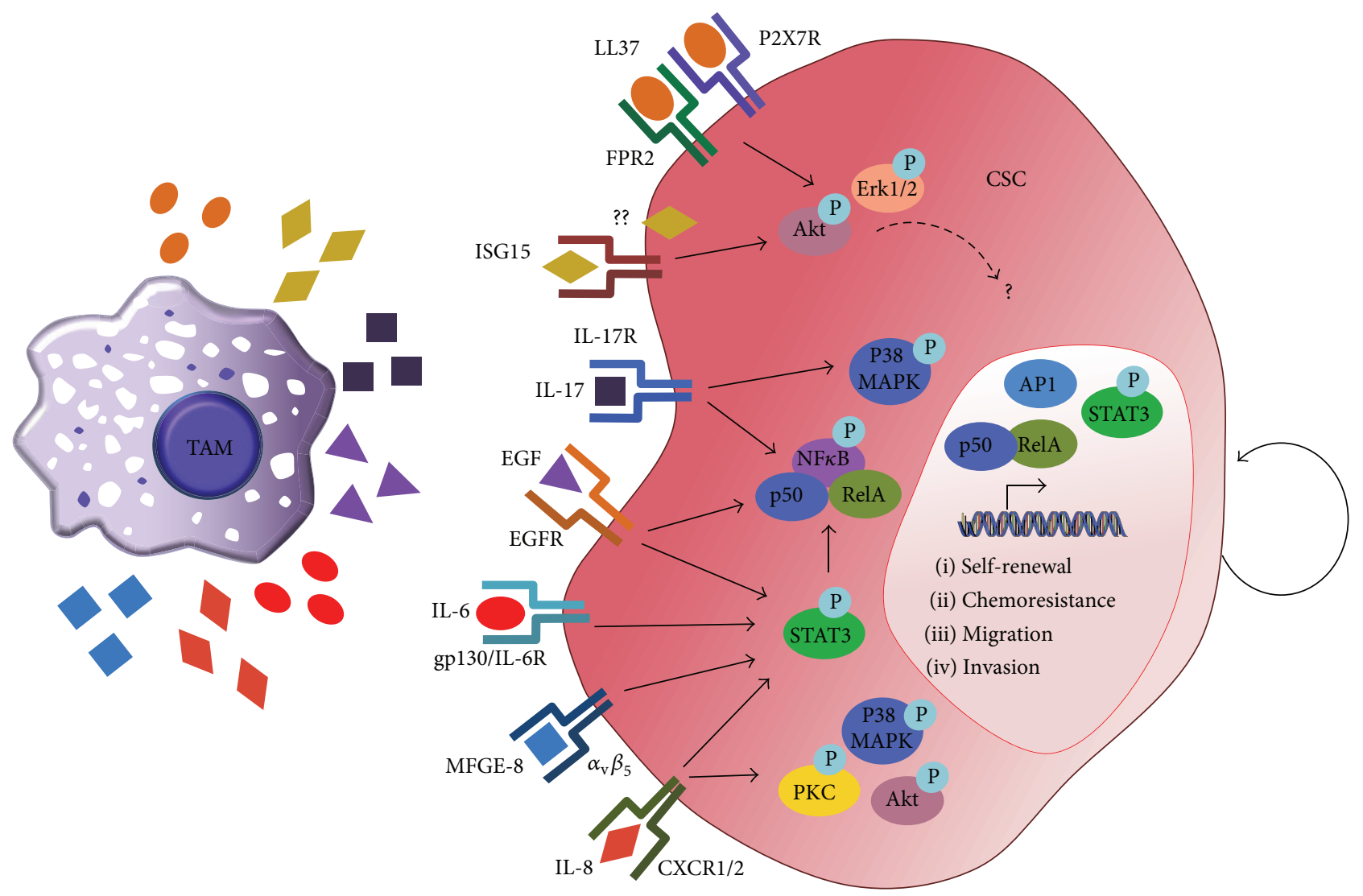

Figure 4: TAM-secreted factors regulate CSC phenotypes. TAMs have been shown to secrete LL-37, ISG15, IL-17, EGF, IL-6, MFGE-8, and IL-8 (among others), which in turn activate MAPK, STAT3/NF $\mathcal{B}$, and other yet-to-be-defined signaling pathways, leading to the activation of CSC properties, such as self-renewal, chemoresistance, migration, and invasion.

monoclonal antibodies allows for increased phagocytosis of cancer cells in vitro and decreased tumor burden in vivo $[162,163,165,166]$. Recent work by Cioffi et al. has extended these findings to show that anti-CD47 therapy can essentially turn the tide on the relationship between CSCs and TAMs, facilitating effective phagocytosis of pancreatic CSCs, which can be further augmented with standard chemotherapeutic agents like gemcitabine or Abraxane [162]. These findings suggest that CD47 inhibition in the adjuvant setting may be an effective means for treating PDAC and potentially other cancers; however future preclinical and clinical studies will need to be performed. As we gain a better understanding of the relationship between TAM and CSCs at each stage of tumor development and progression, we will undoubtedly discover new means to interfere with the TAM-CSC cross talk.

\section{Concluding Remarks}

In this review, we discussed several TAM-derived factors that promote stemness and are thus potential therapeutic targets (summarized in Figure 4). The studies of the past decade have led to significant advances of our understanding of the molecular pathways regulating TAMs and CSCs; however, we are only beginning to put together the pieces that constitute the complex TAM-CSC cross talk that occurs within the host. Increasing evidence suggests that a stemlike niche composed of numerous cell types, including macrophages, is important for promoting CSC self-renewal and maintenance, and likewise, CSC-derived factors induce protumor signals in TAMs. Our current knowledge of CSCs heavily relies on tumor transplantation assays in both syngeneic and xenograft models, the latter of which does not recapitulate the complex microenvironment in which spontaneous tumor initiation occurs, nor can xenograft models accurately mimic human CSC and human TAM interactions. While many immunecompromised mice express macrophages, the macrophage response is typically elevated in these mice and it is uncertain as to whether murine macrophages communicate with human CSCs in the same way as their human counterparts. Thus, until we develop mouse models with humanized immune systems that can support the growth of human primary tumors, we will continue to rely on excellent in vitro systems and syngeneic mouse models to better facilitate our understanding of the relationship between TAMs and CSCs and the eventual development of novel compounds to inhibit this unconventional dependence. 


\section{Conflict of Interests}

The authors declare that there is no conflict of interests.

\section{Acknowledgments}

This work was supported by a Rámon y Cajal Merit Award from the Ministerio de Economía y Competitividad, Spain (Bruno Sainz Jr.), a Clinic and Laboratory Integration Program (CLIP) grant from the Cancer Research Institute, NY (Bruno Sainz Jr.), and an NIH/NCI R00 (CA154605, Heather L. Machado).

\section{References}

[1] A. Kreso and J. E. Dick, "Evolution of the cancer stem cell model," Cell Stem Cell, vol. 14, no. 3, pp. 275-291, 2014.

[2] R. Virchow, "An address on the value of pathological experiments," The British Medical Journal, vol. 2, no. 1075, pp. 198-203, 1881.

[3] T. Lapidot, C. Sirard, J. Vormoor et al., "A cell initiating human acute myeloid leukaemia after transplantation into SCID mice," Nature, vol. 367, no. 6464, pp. 645-648, 1994.

[4] C. Li, D. G. Heidt, P. Dalerba et al., "Identification of pancreatic cancer stem cells," Cancer Research, vol. 67, no. 3, pp. 1030-1037, 2007.

[5] P. C. Hermann, S. L. Huber, T. Herrler et al., "Distinct populations of cancer stem cells determine tumor growth and metastatic activity in human pancreatic cancer," Cell Stem Cell, vol. 1, no. 3, pp. 313-323, 2007.

[6] M. Al-Hajj, M. S. Wicha, A. Benito-Hernandez, S. J. Morrison, and M. F. Clarke, "Prospective identification of tumorigenic breast cancer cells," Proceedings of the National Academy of Sciences of the United States of America, vol. 100, no. 7, pp. 39833988, 2003.

[7] A. Eramo, L. Ricci-Vitiani, A. Zeuner et al., "Chemotherapy resistance of glioblastoma stem cells," Cell Death \& Differentiation, vol. 13, no. 7, pp. 1238-1241, 2006.

[8] I. Miranda-Lorenzo, J. Dorado, E. Lonardo et al., "Intracellular autofluorescence: a biomarker for epithelial cancer stem cells," Nature Methods, vol. 11, no. 11, pp. 1161-1169, 2014.

[9] M. E. Prince, R. Sivanandan, A. Kaczorowski et al., "Identification of a subpopulation of cells with cancer stem cell properties in head and neck squamous cell carcinoma," Proceedings of the National Academy of Sciences of the United States of America, vol. 104, no. 3, pp. 973-978, 2007.

[10] C. A. O’Brien, A. Pollett, S. Gallinger, and J. E. Dick, “A human colon cancer cell capable of initiating tumour growth in immunodeficient mice," Nature, vol. 445, no. 7123, pp. 106-110, 2007.

[11] L. Ricci-Vitiani, D. G. Lombardi, E. Pilozzi et al., "Identification and expansion of human colon-cancer-initiating cells," Nature, vol. 445, no. 7123, pp. 111-115, 2007.

[12] L. Patrawala, T. Calhoun, R. Schneider-Broussard et al., "Highly purified $\mathrm{CD} 44^{+}$prostate cancer cells from xenograft human tumors are enriched in tumorigenic and metastatic progenitor cells," Oncogene, vol. 25, no. 12, pp. 1696-1708, 2006.

[13] T. Schatton, G. F. Murphy, N. Y. Frank et al., "Identification of cells initiating human melanomas," Nature, vol. 451, no. 7176, pp. 345-349, 2008.
[14] E. Quintana, M. Shackleton, M. S. Sabel, D. R. Fullen, T. M. Johnson, and S. J. Morrison, "Efficient tumour formation by single human melanoma cells," Nature, vol. 456, no. 7222, pp. 593-598, 2008.

[15] S. K. Singh, C. Hawkins, I. D. Clarke et al., "Identification of human brain tumour initiating cells," Nature, vol. 432, no. 7015, pp. 396-401, 2004.

[16] L. V. Nguyen, R. Vanner, P. Dirks, and C. J. Eaves, "Cancer stem cells: an evolving concept," Nature Reviews Cancer, vol. 12, no. 2, pp. 133-143, 2012.

[17] K. Ishizawa, Z. A. Rasheed, R. Karisch et al., "Tumor-initiating cells are rare in many human tumors," Cell Stem Cell, vol. 7, no. 3, pp. 279-282, 2010.

[18] T. Reya, S. J. Morrison, M. F. Clarke, and I. L. Weissman, "Stem cells, cancer, and cancer stem cells," Nature, vol. 414, no. 6859, pp. 105-111, 2001.

[19] A. Merlos-Suárez, F. M. Barriga, P. Jung et al., "The intestinal stem cell signature identifies colorectal cancer stem cells and predicts disease relapse," Cell Stem Cell, vol. 8, no. 5, pp. 511-524, 2011.

[20] S. Pece, D. Tosoni, S. Confalonieri et al., "Biological and molecular heterogeneity of breast cancers correlates with their cancer stem cell content," Cell, vol. 140, no. 1, pp. 62-73, 2010.

[21] M. Todaro, M. G. Francipane, J. P. Medema, and G. Stassi, "Colon cancer stem cells: promise of targeted therapy," Gastroenterology, vol. 138, no. 6, pp. 2151-2162, 2010.

[22] J. H. Bae, S. H. Park, J. H. Yang, K. Yang, and J. M. Yi, “Stem celllike gene expression signature identified in ionizing radiationtreated cancer cells," Gene, vol. 572, no. 2, pp. 285-291, 2015.

[23] A. Kreso, C. A. O'Brien, P. van Galen et al., "Variable clonal repopulation dynamics influence chemotherapy response in colorectal cancer," Science, vol. 339, no. 6119, pp. 543-548, 2013.

[24] S. Dingwall, J. B. Lee, B. Guezguez et al., "Neoplastic human embryonic stem cells as a model of radiation resistance of human cancer stem cells," Oncotarget, vol. 6, no. 26, pp. 2225822269, 2015.

[25] M. C. Santos, P. B. Silva, C. O. Rodini et al., "Embryonic stem cell-related protein L1TD1 is required for cell viability, neurosphere formation, and chemoresistance in medulloblastoma," Stem Cells and Development, vol. 24, no. 22, pp. 2700-2708, 2015.

[26] L. E. Santaliz-Ruiz IV, X. Xie, M. Old, T. N. Teknos, and Q. Pan, "Emerging role of nanog in tumorigenesis and cancer stem cells," International Journal of Cancer, vol. 135, no. 12, pp. 27412748, 2014.

[27] Y.-C. Hsu and E. Fuchs, "A family business: stem cell progeny join the niche to regulate homeostasis," Nature Reviews Molecular Cell Biology, vol. 13, no. 2, pp. 103-114, 2012.

[28] V. Plaks, N. Kong, Z. Werb, and V. Plaks, "The cancer stem cell niche: how essential is the niche in regulating stemness of tumor cells?" Cell Stem Cell, vol. 16, no. 3, pp. 225-238, 2015.

[29] M. Hidalgo, "New insights into pancreatic cancer biology," Annals of Oncology, vol. 23, supplement 10, pp. x135-x138, 2012.

[30] D. Hanahan and L. M. Coussens, "Accessories to the crime: functions of cells recruited to the tumor microenvironment," Cancer Cell, vol. 21, no. 3, pp. 309-322, 2012.

[31] H. Korkaya, S. Liu, and M. S. Wicha, "Breast cancer stem cells, cytokine networks, and the tumor microenvironment," The Journal of Clinical Investigation, vol. 121, no. 10, pp. 38043809, 2011. 
[32] D. G. DeNardo, D. J. Brennan, E. Rexhepaj et al., "Leukocyte complexity predicts breast cancer survival and functionally regulates response to chemotherapy," Cancer Discovery, vol. 1, no. 1, pp. 54-67, 2011.

[33] E. Lonardo, J. Frias-Aldeguer, P. C. Hermann, and C. Heeschen, "Pancreatic stellate cells form a niche for cancer stem cells and promote their self-renewal and invasiveness," Cell Cycle, vol. 11, no. 7, pp. 1282-1290, 2012.

[34] J. W. Pollard, "Trophic macrophages in development and disease," Nature Reviews Immunology, vol. 9, no. 4, pp. 259-270, 2009.

[35] E. Fessler, F. E. Dijkgraaf, F. De Sousa E Melo, and J. P. Medema, "Cancer stem cell dynamics in tumor progression and metastasis: is the microenvironment to blame?" Cancer Letters, vol. 341, no. 1, pp. 97-104, 2013.

[36] E. Lonardo, P. C. Hermann, M.-T. Mueller et al., "Nodal/activin signaling drives self-renewal and tumorigenicity of pancreatic cancer stem cells and provides a target for combined drug therapy," Cell Stem Cell, vol. 9, no. 5, pp. 433-446, 2011.

[37] S. Liu, C. Ginestier, S. J. Ou et al., "Breast cancer stem cells are regulated by mesenchymal stem cells through cytokine networks," Cancer Research, vol. 71, no. 2, pp. 614-624, 2011.

[38] H.-J. Li, F. Reinhardt, H. R. Herschman, and R. A. Weinberg, "Cancer-stimulated mesenchymal stem cells create a carcinoma stem cell niche via prostaglandin $\mathrm{E}_{2}$ signaling," Cancer Discovery, vol. 2, no. 9, pp. 840-855, 2012.

[39] I. Malanchi, A. Santamaria-Martínez, E. Susanto et al., "Interactions between cancer stem cells and their niche govern metastatic colonization," Nature, vol. 481, no. 7379, pp. 85-89, 2012.

[40] G. Yu, Y. Jing, X. Kou et al., "Hepatic stellate cells secreted hepatocyte growth factor contributes to the chemoresistance of hepatocellular carcinoma," PLoS ONE, vol. 8, no. 9, Article ID e73312, 2013.

[41] S. M. Cabarcas, L. A. Mathews, and W. L. Farrar, "The cancer stem cell niche-there goes the neighborhood?” International Journal of Cancer, vol. 129, no. 10, pp. 2315-2327, 2011.

[42] R. Noy and J. W. Pollard, "Tumor-associated macrophages: from mechanisms to therapy," Immunity, vol. 41, no. 1, pp. 49-61, 2014.

[43] L. Bingle, N. J. Brown, and C. E. Lewis, "The role of tumourassociated macrophages in tumour progression: implications for new anticancer therapies," Journal of Pathology, vol. 196, no. 3, pp. 254-265, 2002.

[44] B.-Z. Qian and J. W. Pollard, "Macrophage diversity enhances tumor progression and metastasis," Cell, vol. 141, no. 1, pp. 3951, 2010 .

[45] R. M. Steinman and J. Idoyaga, "Features of the dendritic cell lineage," Immunological Reviews, vol. 234, no. 1, pp. 5-17, 2010.

[46] M. Heusinkveld and S. H. van der Burg, "Identification and manipulation of tumor associated macrophages in human cancers," Journal of Translational Medicine, vol. 9, article 216, 2011.

[47] P. J. Murray, J. E. Allen, S. K. Biswas et al., "Macrophage activation and polarization: nomenclature and experimental guidelines," Immunity, vol. 41, no. 1, pp. 14-20, 2014.

[48] C. V. Jones and S. D. Ricardo, "Macrophages and CSF-1: implications for development and beyond," Organogenesis, vol. 9, no. 4, pp. 249-260, 2013.
[49] A. Sica and A. Mantovani, "Macrophage plasticity and polarization: in vivo veritas," Journal of Clinical Investigation, vol. 122, no. 3, pp. 787-795, 2012.

[50] S. Gordon and F. O. Martinez, "Alternative activation of macrophages: mechanism and functions," Immunity, vol. 32, no. 5, pp. 593-604, 2010.

[51] E. Bonavita, M. R. Galdiero, S. Jaillon et al., "Phagocytes as corrupted policemen in cancer-related inflammation," Advances in Cancer Research, vol. 128, pp. 141-171, 2015.

[52] E. Bonavita, S. Gentile, M. Rubino et al., "PTX3 is an extrinsic oncosuppressor regulating complement-dependent inflammation in cancer," Cell, vol. 160, no. 4, pp. 700-714, 2015.

[53] S. K. Biswas and A. Mantovani, "Macrophage plasticity and interaction with lymphocyte subsets: cancer as a paradigm," Nature Immunology, vol. 11, no. 10, pp. 889-896, 2010.

[54] D. M. Mosser and J. P. Edwards, "Exploring the full spectrum of macrophage activation," Nature Reviews Immunology, vol. 8, no. 12, pp. 958-969, 2008.

[55] M. Heusinkveld, P. J. de Vos van Steenwijk, R. Goedemans et al., "M2 macrophages induced by prostaglandin $\mathrm{E}_{2}$ and IL- 6 from cervical carcinoma are switched to activated M1 macrophages by $\mathrm{CD}^{+}$Thl cells," The Journal of Immunology, vol. 187, no. 3, pp. 1157-1165, 2011.

[56] F. O. Martinez, L. Helming, and S. Gordon, "Alternative activation of macrophages: an immunologic functional perspective," Annual Review of Immunology, vol. 27, pp. 451-483, 2009.

[57] D. Laoui, K. Movahedi, E. Van Overmeire et al., "Tumorassociated macrophages in breast cancer: distinct subsets, distinct functions," International Journal of Developmental Biology, vol. 55, no. 7-9, pp. 861-867, 2011.

[58] F. O. Martinez, S. Gordon, M. Locati, and A. Mantovani, “Transcriptional profiling of the human monocyte-to-macrophage differentiation and polarization: new molecules and patterns of gene expression," The Journal of Immunology, vol. 177, no. 10, pp. 7303-7311, 2006.

[59] A. Mantovani, S. Sozzani, M. Locati, P. Allavena, and A. Sica, "Macrophage polarization: tumor-associated macrophages as a paradigm for polarized M2 mononuclear phagocytes," Trends in Immunology, vol. 23, no. 11, pp. 549-555, 2002.

[60] W. Yan, X. Liu, H. Ma et al., “Tim-3 fosters HCC development by enhancing TGF- $\beta$-mediated alternative activation of macrophages," Gut, vol. 64, no. 10, pp. 1593-1604, 2015.

[61] V. Gocheva, H.-W. Wang, B. B. Gadea et al., "IL-4 induces cathepsin protease activity in tumor-associated macrophages to promote cancer growth and invasion," Genes and Development, vol. 24, no. 3, pp. 241-255, 2010.

[62] Y. Nagakawa, T. Aoki, K. Kasuya, A. Tsuchida, and Y. Koyanagi, "Histologic features of venous invasion, expression of vascular endothelial growth factor and matrix metalloproteinase-2 and matrix metalloproteinase-9, and the relation with liver metastasis in pancreatic cancer," Pancreas, vol. 24, no. 2, pp. 169-178, 2002.

[63] R. Wang, J. Zhang, S. Chen et al., “Tumor-associated macrophages provide a suitable microenvironment for non-small lung cancer invasion and progression," Lung Cancer, vol. 74, no. 2, pp. 188-196, 2011.

[64] S. Sousa, R. Brion, M. Lintunen et al., "Human breast cancer cells educate macrophages toward the M2 activation status," Breast Cancer Research, vol. 17, no. 1, article 101, 2015. 
[65] L. R. Bohrer and K. L. Schwertfeger, "Macrophages promote fibroblast growth factor receptor-driven tumor cell migration and invasion in a CXCR2-dependent manner," Molecular Cancer Research, vol. 10, no. 10, pp. 1294-1305, 2012.

[66] W. Fang, L. Ye, L. Shen et al., “Tumor-associated macrophages promote the metastatic potential of thyroid papillary cancer by releasing CXCL8," Carcinogenesis, vol. 35, no. 8, pp. 1780-1787, 2014.

[67] X.-Z. Ye, S.-L. Xu, Y.-H. Xin et al., "Tumor-associated microglia/ macrophages enhance the invasion of glioma stem-like cells via TGF- $\beta 1$ signaling pathway," The Journal of Immunology, vol. 189, no. 1, pp. 444-453, 2012.

[68] R. Singh, B. S. Shankar, and K. B. Sainis, "TGF-betal-ROSATM-CREB signaling axis in macrophage mediated migration of human breast cancer MCF7 cells," Cellular Signalling, vol. 26, no. 7, pp. 1604-1615, 2014.

[69] D. Li, X. Wang, J.-L. Wu et al., “Tumor-produced versican V1 enhances hCAP18/LL-37 expression in macrophages through activation of TLR2 and vitamin D3 signaling to promote ovarian cancer progression in vitro," PLoS ONE, vol. 8, no. 2, Article ID e56616, 2013.

[70] B. Sainz Jr., S. Alcala, E. Garcia et al., "Microenvironmental hCAP-18/LL-37 promotes pancreatic ductal adenocarcinoma by activating its cancer stem cell compartment," Gut, vol. 64, no. 12, pp. 1921-1935, 2015.

[71] E. Y. Lin, J.-F. Li, L. Gnatovskiy et al., "Macrophages regulate the angiogenic switch in a mouse model of breast cancer," Cancer Research, vol. 66, no. 23, pp. 11238-11246, 2006.

[72] C. Murdoch, M. Muthana, S. B. Coffelt, and C. E. Lewis, "The role of myeloid cells in the promotion of tumour angiogenesis," Nature Reviews Cancer, vol. 8, no. 8, pp. 618-631, 2008.

[73] A. Mantovani, P. Allavena, A. Sica, and F. Balkwill, "Cancerrelated inflammation," Nature, vol. 454, no. 7203, pp. 436-444, 2008.

[74] A. Sica, T. Schioppa, A. Mantovani, and P. Allavena, "Tumourassociated macrophages are a distinct M2 polarised population promoting tumour progression: potential targets of anti-cancer therapy," European Journal of Cancer, vol. 42, no. 6, pp. 717-727, 2006.

[75] M. R. Galdiero, E. Bonavita, I. Barajon, C. Garlanda, A. Mantovani, and S. Jaillon, "Tumor associated macrophages and neutrophils in cancer," Immunobiology, vol. 218, no. 11, pp. 14021410, 2013.

[76] C. Raggi, H. S. Mousa, M. Correnti, A. Sica, and P. Invernizzi, "Cancer stem cells and tumor-associated macrophages: a roadmap for multitargeting strategies," Oncogene, 2015.

[77] M. R. Alison, S. Islam, and N. A. Wright, "Stem cells in cancer: instigators and propagators?" Journal of Cell Science, vol. 123, part 14, pp. 2357-2368, 2010.

[78] H. Korkaya, S. Liu, and M. S. Wicha, "Regulation of cancer stem cells by cytokine networks: attacking cancer's inflammatory roots," Clinical Cancer Research, vol. 17, no. 19, pp. 6125-6129, 2011.

[79] E. M. Moran, "Epidemiological and clinical aspects of nonsteroidal anti-inflammatory drugs and cancer risks," Journal of Environmental Pathology, Toxicology and Oncology, vol. 21, no. 2, pp. 193-201, 2002.

[80] M. Karin and F. R. Greten, "NF-kappaB: linking inflammation and immunity to cancer development and progression," Nature Reviews Immunology, vol. 5, no. 10, pp. 749-759, 2005.
[81] F. R. Greten, L. Eckmann, T. F. Greten et al., "IKK $\beta$ links inflammation and tumorigenesis in a mouse model of colitisassociated cancer," Cell, vol. 118, no. 3, pp. 285-296, 2004.

[82] J. Bollrath, T. J. Phesse, V. A. von Burstin et al., "gp130-mediated Stat3 activation in enterocytes regulates cell survival and cell-cycle progression during colitis-associated tumorigenesis," Cancer Cell, vol. 15, no. 2, pp. 91-102, 2009.

[83] F. Colotta, P. Allavena, A. Sica, C. Garlanda, and A. Mantovani, "Cancer-related inflammation, the seventh hallmark of cancer: links to genetic instability," Carcinogenesis, vol. 30, no. 7, pp. 1073-1081, 2009.

[84] M. Kortylewski, H. Xin, M. Kujawski et al., "Regulation of the IL-23 and IL-12 balance by Stat3 signaling in the tumor microenvironment," Cancer Cell, vol. 15, no. 2, pp. 114-123, 2009.

[85] H. L. LaMarca, A. P. Visbal, C. J. Creighton et al., "CCAAT/enhancer binding protein beta regulates stem cell activity and specifies luminal cell fate in the mammary gland," STEM CELLS, vol. 28, no. 3, pp. 535-544, 2010.

[86] S. Maeda, H. Kamata, J.-L. Luo, H. Leffert, and M. Karin, "IKK $\beta$ couples hepatocyte death to cytokine-driven compensatory proliferation that promotes chemical hepatocarcinogenesis," Cell, vol. 121, no. 7, pp. 977-990, 2005.

[87] D. Iliopoulos, H. A. Hirsch, and K. Struhl, "An epigenetic switch involving NF- $\kappa$ B, Lin28, Let-7 MicroRNA, and IL6 links inflammation to celltransformation," Cell, vol. 139, no. 4, pp. 693-706, 2009.

[88] S. Y. Song, M. Gannon, M. K. Washington et al., "Expansion of Pdx1-expressing pancreatic epithelium and islet neogenesis in transgenic mice overexpressing transforming growth factor alpha," Gastroenterology, vol. 117, no. 6, pp. 1416-1426, 1999.

[89] G.-Y. Liou, H. Döppler, B. Necela et al., "Macrophage-secreted cytokines drive pancreatic acinar-to-ductal metaplasia through NF- $\kappa$ B and MMPs," The Journal of Cell Biology, vol. 202, no. 3, pp. 563-577, 2013.

[90] C. Guerra, A. J. Schuhmacher, M. Cañamero et al., "Chronic pancreatitis is essential for induction of pancreatic ductal adenocarcinoma by K-Ras oncogenes in adult mice," Cancer Cell, vol. 11, no. 3, pp. 291-302, 2007.

[91] G.-Y. Liou, H. Döppler, B. Necela et al., "Mutant KRAS-induced expression of ICAM-1 in pancreatic acinar cells causes attraction of macrophages to expedite the formation of precancerous lesions," Cancer Discovery, vol. 5, no. 1, pp. 52-63, 2015.

[92] K. Miyamoto, K. Y. Araki, K. Naka et al., "Foxo3a is essential for maintenance of the hematopoietic stem cell pool," Cell Stem Cell, vol. 1, no. 1, pp. 101-112, 2007.

[93] M. Diehn, R. W. Cho, N. A. Lobo et al., "Association of reactive oxygen species levels and radioresistance in cancer stem cells," Nature, vol. 458, no. 7239, pp. 780-783, 2009.

[94] T. M. Phillips, W. H. McBride, and F. Pajonk, "The response of CD $24^{-/ \text {low }} / \mathrm{CD} 44^{+}$breast cancer-initiating cells to radiation," Journal of the National Cancer Institute, vol. 98, no. 24, pp. 17771785, 2006.

[95] F. Balkwill and A. Mantovani, "Inflammation and cancer: back to Virchow?" The Lancet, vol. 357, no. 9255, pp. 539-545, 2001.

[96] S. P. Gao, K. G. Mark, K. Leslie et al., "Mutations in the EGFR kinase domain mediate STAT3 activation via IL-6 production in human lung adenocarcinomas," Journal of Clinical Investigation, vol. 117, no. 12, pp. 3846-3856, 2007. 
[97] D. J. J. Waugh and C. Wilson, “The interleukin-8 pathway in cancer," Clinical Cancer Research, vol. 14, no. 21, pp. 6735-6741, 2008.

[98] C. Ginestier, S. Liu, M. E. Diebel et al., "CXCR1 blockade selectively targets human breast cancer stem cells in vitro and in xenografts," Journal of Clinical Investigation, vol. 120, no. 2, pp. 485-497, 2010.

[99] P. J. Barnes and M. Karin, "Nuclear factor- $\kappa \mathrm{B}-\mathrm{a}$ pivotal transcription factor in chronic inflammatory diseases," The New England Journal of Medicine, vol. 336, no. 15, pp. 1066-1071, 1997.

[100] S. Wan, E. Zhao, I. Kryczek et al., "Tumor-associated macrophages produce interleukin 6 and signal via STAT3 to promote expansion of human hepatocellular carcinoma stem cells," Gastroenterology, vol. 147, no. 6, pp. 1393-1404, 2014.

[101] J. B. Mitchem, D. J. Brennan, B. L. Knolhoff et al., "Targeting tumor-infiltrating macrophages decreases tumor-initiating cells, relieves immunosuppression, and improves chemotherapeutic responses," Cancer Research, vol. 73, no. 3, pp. 1128-1141, 2013.

[102] S. Le Gouvello, S. Bastuji-Garin, N. Aloulou et al., "High prevalence of Foxp3 and IL17 in MMR-proficient colorectal carcinomas," Gut, vol. 57, no. 6, pp. 772-779, 2008.

[103] Y. Miyahara, K. Odunsi, W. Chen, G. Peng, J. Matsuzaki, and R.-F. Wang, "Generation and regulation of human CD4+ IL-17producing T cells in ovarian cancer," Proceedings of the National Academy of Sciences of the United States of America, vol. 105, no. 40, pp. 15505-15510, 2008.

[104] K. S. Sfanos, T. C. Bruno, C. H. Maris et al., "Phenotypic analysis of prostate-infiltrating lymphocytes reveals $\mathrm{T}_{\mathrm{H}} 17$ and $\mathrm{T}_{\text {reg }}$ skewing," Clinical Cancer Research, vol. 14, no. 11, pp. 32543261, 2008.

[105] X. Zhu, L. A. Mulcahy, R. A. A. Mohammed et al., "IL-17 expression by breast-cancer-associated macrophages: IL-17 promotes invasiveness of breast cancer cell lines," Breast Cancer Research, vol. 10, no. 6, article R95, 2008.

[106] T. Xiang, H. Long, L. He et al., "Interleukin-17 produced by tumor microenvironment promotes self-renewal of $\mathrm{CD}_{133^{+}}$ cancer stem-like cells in ovarian cancer," Oncogene, vol. 34, no. 2, pp. 165-176, 2015.

[107] R. Ward, A. H. Sims, A. Lee et al., "Monocytes and macrophages, implications for breast cancer migration and stem cell-like activity and treatment," Oncotarget, vol. 6, no. 16, pp. 1468714699, 2015.

[108] S. Goswami, E. Sahai, J. B. Wyckoff et al., "Macrophages promote the invasion of breast carcinoma cells via a colonystimulating factor-1/epidermal growth factor paracrine loop," Cancer Research, vol. 65, no. 12, pp. 5278-5283, 2005.

[109] J. Yang, D. Liao, C. Chen et al., "Tumor-associated macrophages regulate murine breast cancer stem cells through a novel paracrine EGFR/Stat3/Sox-2 signaling pathway," STEM CELLS, vol. 31, no. 2, pp. 248-258, 2013.

[110] O. Leis, A. Eguiara, E. Lopez-Arribillaga et al., "Sox2 expression in breast tumours and activation in breast cancer stem cells," Oncogene, vol. 31, no. 11, pp. 1354-1365, 2012.

[111] N. Tiwari, V. K. Tiwari, L. Waldmeier et al., "Sox4 is a master regulator of epithelial-mesenchymal transition by controlling Ezh2 expression and epigenetic reprogramming," Cancer Cell, vol. 23, no. 6, pp. 768-783, 2013.

[112] C.-J. Chang, J.-Y. Yang, W. Xia et al., "EZH2 promotes expansion of breast tumor initiating cells through activation of RAF1- $\beta$ catenin signaling," Cancer Cell, vol. 19, no. 1, pp. 86-100, 2011.
[113] H. Lu, K. R. Clauser, W. L. Tam et al., "A breast cancer stem cell niche supported by juxtacrine signalling from monocytes and macrophages," Nature Cell Biology, vol. 16, no. 11, pp. 1105-1117, 2014.

[114] M. Jinushi, M. Sato, A. Kanamoto et al., "Milk fat globule epidermal growth factor-8 blockade triggers tumor destruction through coordinated cell-autonomous and immune-mediated mechanisms," The Journal of Experimental Medicine, vol. 206, no. 6, pp. 1317-1326, 2009.

[115] W. Zhou, S. Q. Ke, Z. Huang et al., "Periostin secreted by glioblastoma stem cells recruits M2 tumour-associated macrophages and promotes malignant growth," Nature Cell Biology, vol. 17, no. 2, pp. 170-182, 2015.

[116] B. Sainz Jr., B. Martín, M. Tatari, C. Heeschen, and S. Guerra, "ISG15 is a critical microenvironmental factor for pancreatic cancer stem cells," Cancer Research, vol. 74, no. 24, pp. 73097320, 2014.

[117] M.-J. Brissette, S. Lepage, A.-S. Lamonde et al., "MFGE8 released by apoptotic endothelial cells triggers antiinflammatory macrophage reprogramming," PLoS ONE, vol. 7, no. 4, Article ID e36368, 2012.

[118] E. Y. Lin, A. V. Nguyen, R. G. Russell, and J. W. Pollard, "Colonystimulating factor 1 promotes progression of mammary tumors to malignancy," The Journal of Experimental Medicine, vol. 193, no. 6, pp. 727-740, 2001.

[119] P. Rodrigues, F. O. Hering, and A. Meller, "Adjuvant effect of IV clodronate on the delay of bone metastasis in high-risk prostate cancer patients: a prospective study," Cancer Research and Treatment, vol. 43, no. 4, pp. 231-235, 2011.

[120] W. Zhang, X.-D. Zhu, H.-C. Sun et al., "Depletion of tumorassociated macrophages enhances the effect of sorafenib in metastatic liver cancer models by antimetastatic and antiangiogenic effects," Clinical Cancer Research, vol. 16, no. 13, pp. 34203430, 2010.

[121] I. Baccelli, A. Schneeweiss, S. Riethdorf et al., "Identification of a population of blood circulating tumor cells from breast cancer patients that initiates metastasis in a xenograft assay," Nature Biotechnology, vol. 31, no. 6, pp. 539-544, 2013.

[122] E. Zoni, G. van der Horst, A. F. van de Merbel et al., "miR-25 modulates invasiveness and dissemination of human prostate cancer cells via regulation of $\alpha_{\mathrm{v}}$ - and $\alpha_{6}$-integrin expression," Cancer Research, vol. 75, no. 11, pp. 2326-2336, 2015.

[123] C. L. Hodgkinson, C. J. Morrow, Y. Li et al., "Tumorigenicity and genetic profiling of circulating tumor cells in small-cell lung cancer," Nature Medicine, vol. 20, no. 8, pp. 897-903, 2014.

[124] A. Cano, P. G. Santamaría, and G. Moreno-Bueno, "LOXL2 in epithelial cell plasticity and tumor progression," Future Oncology, vol. 8, no. 9, pp. 1095-1108, 2012.

[125] N. Takebe, R. Q. Warren, and S. P. Ivy, "Breast cancer growth and metastasis: interplay between cancer stem cells, embryonic signaling pathways and epithelial-to-mesenchymal transition," Breast Cancer Research, vol. 13, no. 3, p. 211, 2011.

[126] Q.-M. Fan, Y.-Y. Jing, G.-F. Yu et al., “Tumor-associated macrophages promote cancer stem cell-like properties via transforming growth factor-betal-induced epithelial-mesenchymal transition in hepatocellular carcinoma," Cancer Letters, vol. 352, no. 2, pp. 160-168, 2014.

[127] S. Su, Q. Liu, J. Chen et al., "A positive feedback loop between mesenchymal-like cancer cells and macrophages is essential to breast cancer metastasis," Cancer Cell, vol. 25, no. 5, pp. 605620, 2014. 
[128] C.-H. Lee, S.-Y. Liu, K.-C. Chou et al., "Tumor-associated macrophages promote oral cancer progression through activation of the Axl signaling pathway," Annals of Surgical Oncology, vol. 21, no. 3, pp. 1031-1037, 2014.

[129] C.-Y. Liu, J.-Y. Xu, X.-Y. Shi et al., "M2-polarized tumorassociated macrophages promoted epithelial-mesenchymal transition in pancreatic cancer cells, partially through TLR4/IL10 signaling pathway," Laboratory Investigation, vol. 93, no. 7, pp. 844-854, 2013.

[130] A.-K. Bonde, V. Tischler, S. Kumar, A. Soltermann, and R. A. Schwendener, "Intratumoral macrophages contribute to epithelial-mesenchymal transition in solid tumors," BMC Cancer, vol. 12, article 35, 2012.

[131] C.-Y. Lin, C.-J. Lin, K.-H. Chen, J.-C. Wu, S.-H. Huang, and S.-M. Wang, "Macrophage activation increases the invasive properties of hepatoma cells by destabilization of the adherens junction," FEBS Letters, vol. 580, no. 13, pp. 3042-3050, 2006.

[132] C. H. Zhang, F. L. Guo, G. L. Xu et al., "STAT3 activation mediates epithelial-to-mesenchymal transition in human hepatocellular carcinoma cells," Hepatogastroenterology, vol. 61, no. 132, pp. 1082-1089, 2014.

[133] N. Zhou, Y. Zhang, X. Zhang et al., "Exposure of tumorassociated macrophages to apoptotic MCF-7 cells promotes breast cancer growth and metastasis," International Journal of Molecular Sciences, vol. 16, no. 6, pp. 11966-11982, 2015.

[134] M. Jinushi, S. Chiba, H. Yoshiyama et al., "Tumor-associated macrophages regulate tumorigenicity and anticancer drug responses of cancer stem/initiating cells," Proceedings of the National Academy of Sciences of the United States of America, vol. 108, no. 30, pp. 12425-12430, 2011.

[135] S. A. Mani, W. Guo, M.-J. Liao et al., "The epithelialmesenchymal transition generates cells with properties of stem cells," Cell, vol. 133, no. 4, pp. 704-715, 2008.

[136] S. B. Krantz, M. A. Shields, S. Dangi-Garimella, H. G. Munshi, and D. J. Bentrem, "Contribution of epithelial-to-mesenchymal transition and cancer stem cells to pancreatic cancer progression," Journal of Surgical Research, vol. 173, no. 1, pp. 105-112, 2012.

[137] A. Dovas, A. Patsialou, A. S. Harney, J. Condeelis, and D. Cox, "Imaging interactions between macrophages and tumour cells that are involved in metastasis in vivo and in vitro," Journal of Microscopy, vol. 251, no. 3, pp. 261-269, 2013.

[138] A. E. Powell, E. C. Anderson, P. S. Davies et al., "Fusion between intestinal epithelial cells and macrophages in a cancer context results in nuclear reprogramming," Cancer Research, vol. 71, no. 4, pp. 1497-1505, 2011.

[139] T. Tsubouchi, J. Soza-Ried, K. Brown et al., "DNA synthesis is required for reprogramming mediated by stem cell fusion," Cell, vol. 152, no. 4, pp. 873-883, 2013.

[140] H. M. Schramm, "Should EMT of cancer cells be understood as epithelial-myeloid transition?" Journal of Cancer, vol. 5, no. 2, pp. 125-132, 2014.

[141] J. M. Pawelek and A. K. Chakraborty, "Fusion of tumour cells with bone marrow-derived cells: a unifying explanation for metastasis," Nature Reviews Cancer, vol. 8, no. 5, pp. 377-386, 2008.

[142] J. M. Pawelek and A. K. Chakraborty, "The cancer cellleukocyte fusion theory of metastasis," in Advances in Cancer Research, vol. 101, chapter 10, pp. 397-444, Academic Press, New York, NY, USA, 2008.
[143] G. A. Clawson, G. L. Matters, P. Xin et al., "Macrophage-tumor cell fusions from peripheral blood of melanoma patients," PLoS ONE, vol. 10, no. 8, Article ID e0134320, 2015.

[144] R. Lazova, G. S. LaBerge, E. Duvall et al., "A melanoma brain metastasis with a donor-patient hybrid genome following bone marrow transplantation: first evidence for fusion in human cancer," PLoS ONE, vol. 8, no. 6, Article ID e66731, 2013.

[145] D. L. Adams, S. S. Martin, R. K. Alpaugh et al., "Circulating giant macrophages as a potential biomarker of solid tumors," Proceedings of the National Academy of Sciences of the United States of America, vol. 111, no. 9, pp. 3514-3519, 2014.

[146] K. J. Luzzi, I. C. MacDonald, E. E. Schmidt et al., "Multistep nature of metastatic inefficiency: dormancy of solitary cells after successful extravasation and limited survival of early micrometastases," The American Journal of Pathology, vol. 153, no. 3, pp. 865-873, 1998.

[147] C. W. Wong, A. Lee, L. Shientag et al., "Apoptosis: an early event in metastatic inefficiency," Cancer Research, vol. 61, no. 1, pp. 333-338, 2001.

[148] T. Oskarsson, E. Batlle, and J. Massagué, "Metastatic stem cells: sources, niches, and vital pathways," Cell Stem Cell, vol. 14, no. 3, pp. 306-321, 2014.

[149] S. Liu, Y. Cong, D. Wang et al., "Breast cancer stem cells transition between epithelial and mesenchymal states reflective of their normal counterparts," Stem Cell Reports, vol. 2, no. 1, pp. 78-91, 2014.

[150] M. Balic, H. Lin, L. Young et al., "Most early disseminated cancer cells detected in bone marrow of breast cancer patients have a putative breast cancer stem cell phenotype," Clinical Cancer Research, vol. 12, no. 19, pp. 5615-5621, 2006.

[151] V. Plaks, C. D. Koopman, and Z. Werb, "Circulating tumor cells," Science, vol. 341, no. 6151, pp. 1186-1188, 2013.

[152] B. Qian, Y. Deng, J. H. Im et al., "A distinct macrophage population mediates metastatic breast cancer cell extravasation, establishment and growth," PLoS ONE, vol. 4, no. 8, Article ID e6562, 2009.

[153] R. N. Kaplan, R. D. Riba, S. Zacharoulis et al., "VEGFR1positive haematopoietic bone marrow progenitors initiate the pre-metastatic niche," Nature, vol. 438, no. 7069, pp. 820-827, 2005.

[154] H. W. van Deventer, D. A. Palmieri, Q. P. Wu, E. C. McCook, and J. S. Serody, "Circulating fibrocytes prepare the lung for cancer metastasis by recruiting Ly-6C ${ }^{+}$monocytes via CCL2," The Journal of Immunology, vol. 190, no. 9, pp. 4861-4867, 2013.

[155] A. M. Gil-Bernabé, Š. Ferjančič, M. Tlalka et al., "Recruitment of monocytes/macrophages by tissue factor-mediated coagulation is essential for metastatic cell survival and premetastatic niche establishment in mice," Blood, vol. 119, no. 13, pp. 3164-3175, 2012.

[156] B. Costa-Silva, N. M. Aiello, A. J. Ocean et al., "Pancreatic cancer exosomes initiate pre-metastatic niche formation in the liver," Nature Cell Biology, vol. 17, no. 6, pp. 816-826, 2015.

[157] T. Kitamura, B.-Z. Qian, and J. W. Pollard, "Immune cell promotion of metastasis," Nature Reviews Immunology, vol. 15, no. 2, pp. 73-86, 2015.

[158] G. Germano, R. Frapolli, C. Belgiovine et al., "Role of macrophage targeting in the antitumor activity of trabectedin," Cancer Cell, vol. 23, no. 2, pp. 249-262, 2013.

[159] C. H. Ries, M. A. Cannarile, S. Hoves et al., "Targeting tumorassociated macrophages with anti-CSF-1R antibody reveals 
a strategy for cancer therapy," Cancer Cell, vol. 25, no. 6, pp. 846$859,2014$.

[160] F. Hussain, M. Freissmuth, D. Völkel et al., "Human antimacrophage migration inhibitory factor antibodies inhibit growth of human prostate cancer cells in vitro and in vivo," Molecular Cancer Therapeutics, vol. 12, no. 7, pp. 1223-1234, 2013.

[161] T. Yamashina, M. Baghdadi, A. Yoneda et al., "Cancer stemlike cells derived from chemoresistant tumors have a unique capacity to prime tumorigenic myeloid cells," Cancer Research, vol. 74, no. 10, pp. 2698-2709, 2014.

[162] M. Cioffi, S. Trabulo, M. Hidalgo et al., "Inhibition of CD47 effectively targets pancreatic cancer stem cells via dual mechanisms," Clinical Cancer Research, vol. 21, no. 10, pp. 2325-2337, 2015.

[163] T. K.-W. Lee, V. C.-H. Cheung, P. Lu et al., "Blockade of CD47mediated cathepsin S/protease-activated receptor 2 signaling provides a therapeutic target for hepatocellular carcinoma," Hepatology, vol. 60, no. 1, pp. 179-191, 2014.

[164] T. Matozaki, Y. Murata, H. Okazawa, and H. Ohnishi, "Functions and molecular mechanisms of the CD47-SIRP $\alpha$ signalling pathway," Trends in Cell Biology, vol. 19, no. 2, pp. 72-80, 2009.

[165] K. S. Chan, I. Espinosa, M. Chao et al., "Identification, molecular characterization, clinical prognosis, and therapeutic targeting of human bladder tumor-initiating cells," Proceedings of the National Academy of Sciences of the United States of America, vol. 106, no. 33, pp. 14016-14021, 2009.

[166] R. Majeti, M. P. Chao, A. A. Alizadeh et al., "CD47 is an adverse prognostic factor and therapeutic antibody target on human acute myeloid leukemia stem cells," Cell, vol.138, no. 2, pp. 286299, 2009. 


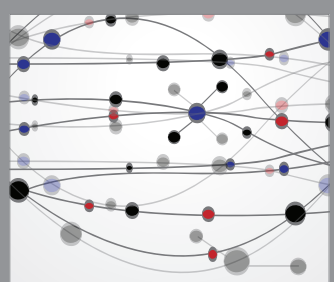

The Scientific World Journal
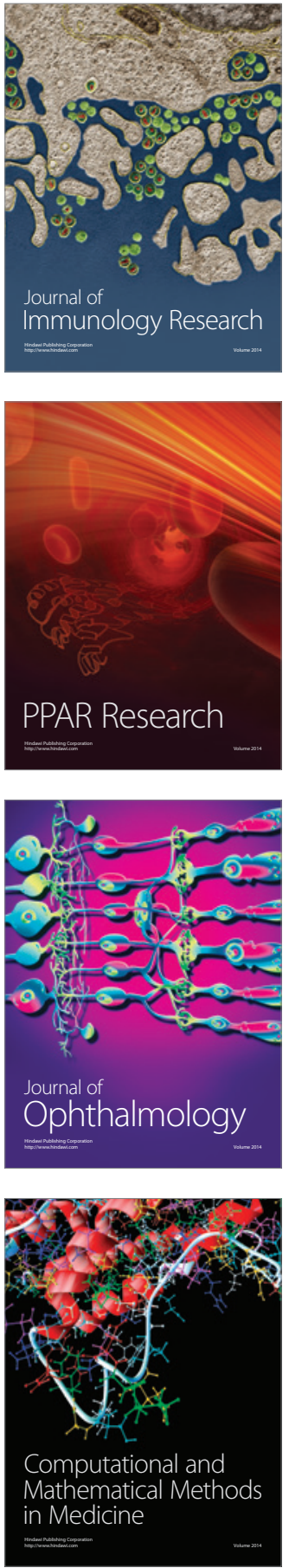

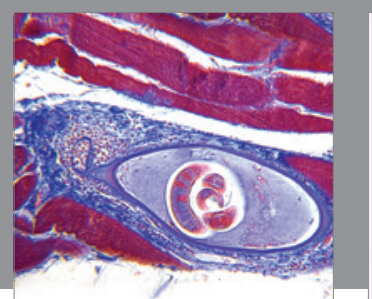

Gastroenterology Research and Practice

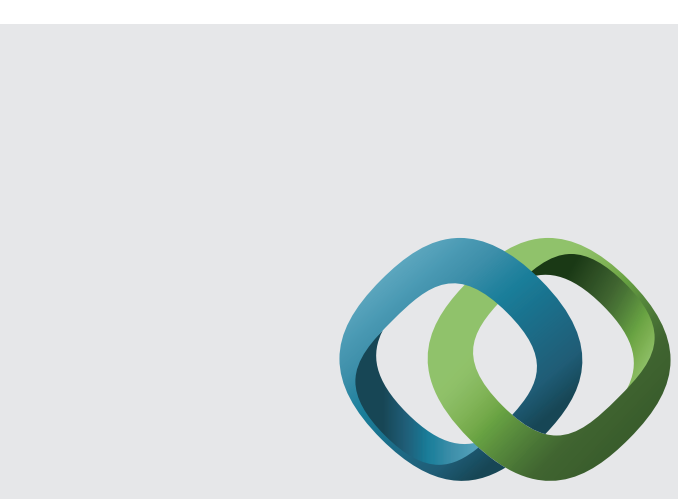

\section{Hindawi}

Submit your manuscripts at

http://www.hindawi.com
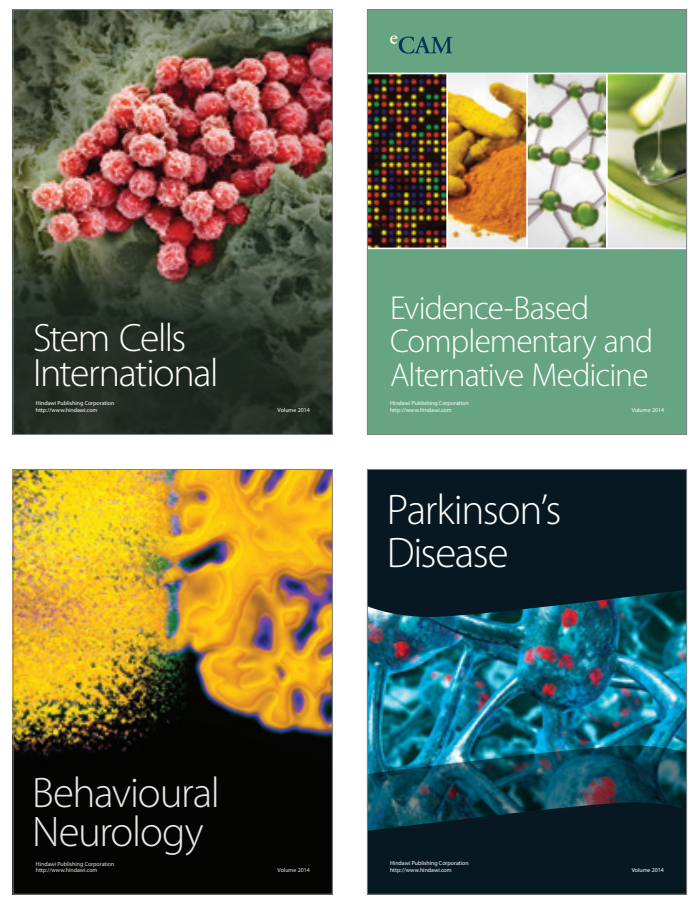
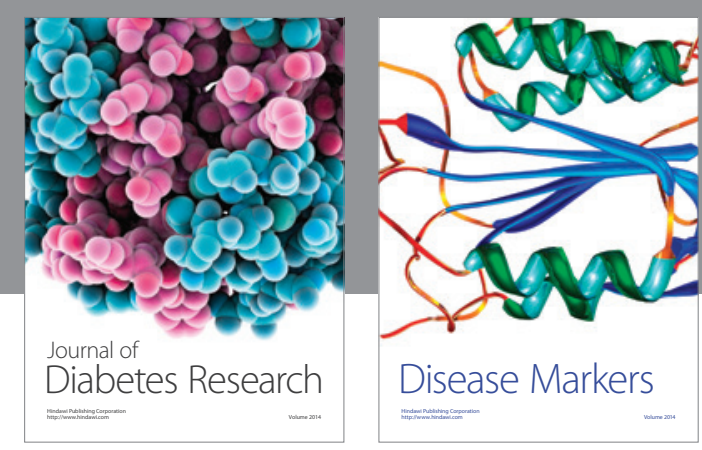

Disease Markers
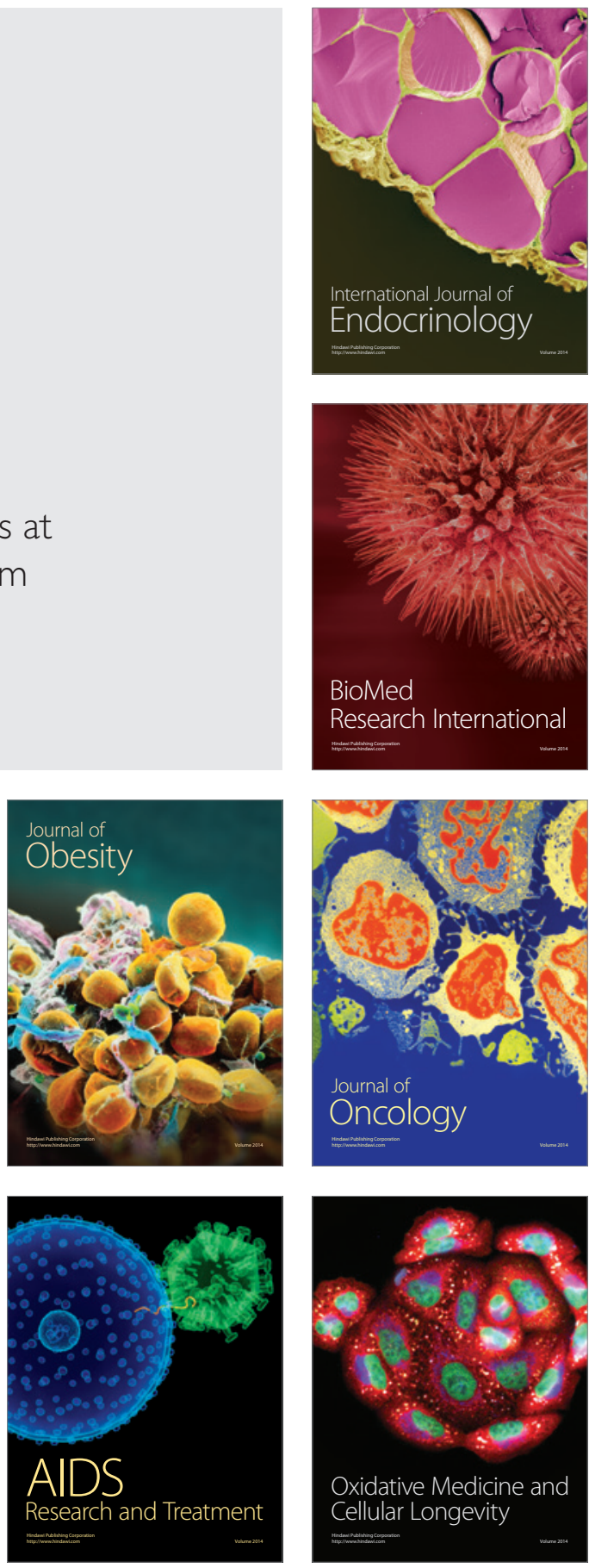